\title{
Prácticas fisicodeportivas: actitud e interés de escolares colombianos
}

\section{Introducción}

T a actitud se entiende como el elemento de la personalidad que ex-

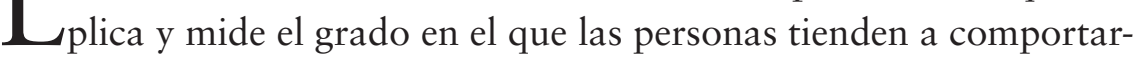
se de manera distinta en situaciones similares (Díaz, 2002). Es decir, aunque el escenario sea semejante, cada sujeto tiene una forma de interpretar, asimilar y responder de manera distintiva ante una situación determinada. En este caso en particular se hace referencia a la respuesta de las personas frente a las prácticas fisicodeportivas.

Son escasas las investigaciones que se han adelantado para determinar las actitudes de las personas frente a la actividad física. Según Theodorakis y Doganis (1992), en torno a la práctica de la actividad física y el deporte los estudios de las actitudes se han orientado hacia las prácticas del alto rendimiento. Sin embargo, se han referenciado también algunos trabajos en poblaciones escolares y de la tercera edad.

Por otra parte, las tendencias son consideradas corrientes o direcciones hacia las cuales se inclina cierto segmento de la población atendiendo a criterios específicos del sector correspondiente. En el ámbito de la práctica de actividades fisicodeportivas las tendencias pueden ser muy variadas y, por lo tanto, dispersas. La gran mayoría de las investigaciones en este campo establecen una agrupación y categorización de los deportes y las actividades físicas, entre otras razones, 
para determinar las tendencias o inclinaciones de las personas hacia dichas prácticas.

Es importante señalar que en la determinación de las tendencias se debe considerar que los resultados no pueden generalizarse ni contextualizarse en el marco de grandes poblaciones. Esto debido a que cada grupo, de acuerdo con Maskatova (1997), puede presentar características diferentes que varían en función de las particularidades genéticas, edad, sexo, maduración de las funciones sicomotoras, diferencias sociales, culturales y étnicas.

\section{Las habilidades fisicodeportivas y su influencia en la adquisición de hábitos deportivos}

De acuerdo con lo expuesto por Romero y Amador (2007), la adquisición de habilidades fisicodeportivas que motiven la formación de hábitos deportivos debe considerar una serie de estrategias estimulantes para que el individuo se anime a continuar practicando regularmente la actividad física seleccionada, perfeccionando sus habilidades motrices hasta que dicha práctica se convierta en un hábito. En este mismo sentido, Delgado y Torres (1998) indica que la actividad física será atrayente para el estudiante en la medida en que cuente con una serie de características e implicaciones didácticas entre las que destacan:

- Debe ser lúdica, saludable y significativa.

- Debe permitir su autonomía y conseguir funcionalidad futura.

- Debe aprovechar y recuperar espacios no utilizados y evitar la infrautilización de los existentes.

- Debe permitir horarios flexibles.

- Debe promover la realización de actividades interdisciplinarias vinculando a otros profesionales. 
En coherencia con lo anterior Wankel y Kreisel (1985) afirman que si predominan las motivaciones extrínsecas, como las de ganar partidos o premios, o agradar a los padres o entrenadores, entonces existen mayores probabilidades de que estos hábitos no perduren, lo que conduce incluso al abandono de toda actividad fisicodeportiva.

En contraste, Brustad (1988) considera que cuando se perciben altos niveles de habilidad y maestría con poca presión por parte de los familiares y gran satisfacción expresada por los entrenadores y padres, se dan las condiciones idóneas para que el adolescente disfrute con la actividad fisicodeportiva. Es decir, tanto la motivación como la ausencia de presión son factores determinantes para realizar una actividad física agradable que conlleve la adquisición de un hábito (Romero y Amador, 2007).

Por otra parte, el grado de satisfacción que ofrece la práctica deportiva viene a incidir directamente en la adquisición de un hábito. Tal como indica Torre (1998), la propia percepción de la habilidad motriz va a incidir en la elección y práctica de determinadas actividades fisicodeportivas y su conversión en hábito.

Así mismo, complementando la anterior argumentación, Sostroem (1978) afirma que el sujeto que percibe en sí un buen nivel de habilidad motriz será el que presente actitudes más positivas hacia el ejercicio físico, lo cual repercutirá en el grado de involucración en sus comportamientos.

Diferentes autores entre los que se encuentran Biddle y Goudas (1994), Fox (1988), Goudas y Biddle (1994), Sánchez (1996)— coinciden en afirmar que para lograr mejorar esta autopercepción durante las clases de educación física, se deben tener en cuenta los siguientes aspectos:

- Estimular más la participación que el rendimiento en entornos favorables, en donde el objetivo será el esfuerzo y la mejora personal y no ser mejor que los demás. Así se reducen las desigualdades por género o habilidad debido a que tradicionalmente las expectativas en torno a la actividad física son más positivas para los chicos que para las chicas. 
- Proporcionar experiencias agradables que, además del placer, estimulen la motivación intrínseca (que empuja al niño a mejorar y aprender nuevas habilidades). Ello depende de la convergencia entre la motivación que impulsa a la actividad física y la manera en que el deseo de "jugar" se satisface durante la participación (Piéron, 1998). Así, el orgullo de lo bien hecho o el desánimo que acompaña al fracaso inciden en dicha motivación y en la autoestima del practicante.

- Informar sobre la importancia de las actividades fisicodeportivas para la salud y favorecer experiencias reflexivas en los estudiantes en conexión directa con lo práctico (componente cognitivo).

- El profesor, los padres y el grupo de compañeros deberían proporcionar feedback positivo.

- Adoptar medidas compensatorias sobre ciertos estudiantes con anomalías funcionales leves. Probar las capacidades personales de los estudiantes, a modo de reto o logro, con objetivos atractivos y progresivamente alcanzables. Así, las clases no se orientarán a la simple búsqueda de diversión, sino que se contemplará su valor educativo.

- Lograr que el estudiante perciba el desarrollo de cierta habilidad y cierta condición física producidas por la actividad deportiva (percepción de competencia), lo cual desembocará en una mayor atracción hacia dicha actividad. Además, conseguir una buena eficiencia técnica repercutirá en un menor consumo energético durante el esfuerzo físico, fundamentalmente en deportes con cierta complejidad técnica, por lo que la actividad se puede prolongar por más tiempo.

- Lograr que los estudiantes comprendan la importancia de una educación física de calidad. 
- Promover el interés por las prácticas fisicodeportivas.

- Valorar las prácticas fisicodeportivas.

- Hacer explícitas las creencias sobre la práctica fisicodeportiva.

En este sentido, se ha propuesto que la clase de Educación Física debe adoptar lineamientos, contenidos y métodos para el desarrollo de la actividad física con miras a preparar a los estudiantes para que asuman estilos de vida saludables (Reynaga, Landeros, Alonso y García, 2013).

\section{Percepción de escolares colombianos sobre la finalidad de las clases de Educación Física}

\section{Sobre el concepto de educación física}

Para una conceptualización de la educación física debemos partir de la etimología de los términos involucrados. En el sintagma educación física la palabra física proviene del latín physicus, que a su vez procede del griego physikós: movimiento de un cuerpo, en este caso del ser humano, compuesto por una materia que aparece de diferente forma, cuya manifestación expresiva es la dynamis.

Es decir, el movimiento es una conexión entre la psiquis y la physis, que se establece como un principio natural, integral y único cuya existencia solo es posible por esa conexión. En este contexto, cualquier movimiento que una persona realiza es el resultado de tan magnífica interacción (Romero y Amador, 2007).

Para Aristóteles lo psíquico es el principio y la causa del movimiento y del reposo, intrínsecos al ser en que residen. Mientras que para Cagigal (1996) lo físico significa lo perteneciente a la constitución y naturaleza corpórea o material, que aplicado al ser humano se entiende como aquello que forma su constitución o naturaleza. 
En esta reflexión se identifican el cuerpo y el valor de lo corporal con el movimiento como su acción resultante. Estos son los componentes que se van a mantener hasta nuestros días.

Aunque el término educación física se sigue manteniendo, sobre todo en el ámbito educativo, hoy se prefiere un término más amplio que no se restrinja a la enseñanza y pueda recoger desde la investigación básica sobre el movimiento o la actividad física general humana, hasta campos aplicados que no sean únicamente educativos como el entrenamiento, la rehabilitación, la recreación, o la gestión deportiva. A ese término genérico, ya sea actividad física, motricidad humana, o movimiento humano, se incorpora la palabra ciencia o ciencias, para significar la orientación científica del ámbito de estudio. (Cagigal, 1996, p. 39)

La educación física es un eficaz instrumento pedagógico, especialmente porque ayuda a desarrollar las cualidades básicas del ser humano como unidad biosicosocial. Además, contribuye al accionar educativo con sus fundamentos científicos y sus vínculos interdisciplinarios, principalmente con la filosofía, la sicología, la biología y la física (Romero y Amador, 2007).

La educación física no es un conjunto de saberes homogéneos y con carácter disciplinar definido, sino la resultante del tratamiento pedagógico de, si se quiere, lo corporal. Es decir, es el tratamiento disciplinar de lo corporal en el sistema educativo:

"Lo motriz se refiere a un modo de construir 'conducta', como objeto científico, proporcionando un hilo conductor y sugiriendo la importancia del estudio de los procesos de comunicación y de decisión de la acción motriz" (Amador, 1994, p. 48-49). La noción de conducta motriz posibilita el análisis de los aspectos cognitivos, afectivos y relacionales implicados en las acciones que incumben acá con toda rigurosidad. Las conductas motrices constituyen un sistema de acción específico del ser humano diferente en su naturaleza a otros tipos de conductas, como las verbales.

Cagigal (1957), por su parte, afirmaba que la educación física es todo tipo de educación del individuo y de la sociedad con especial 
atención a las capacidades físicas humanas. El objeto y sujeto permanente de educación es el ser humano, pero una parte del individuo nunca se educa, solo se adiestra.

Por otro lado, la educación física es considerada un derecho fundamental consagrado en la Carta Internacional de la Educación Física y el Deporte (Unesco, 1978). Y también ha tenido implicaciones conceptuales y epistemológicas variadas, como lo afirma Contecha (2008) en relación con las exigencias propias de cada región y las contingencias sociales relacionadas con el tiempo libre, el ocio, la salud, la recreación, la ecología, la investigación, el deporte competitivo de alto nivel, el juego, la recreación, el entrenamiento deportivo y la administración, entre otros asuntos.

La educación física hasta la década de los noventa tenía un sesgo hacia la enseñanza que la enmarcaba exclusivamente en el ámbito educativo y pedagógico. De tal manera que se consideraba exclusivamente como una de las áreas de formación dentro del plan de estudio en los diferentes grados de escolaridad. Un análisis más amplio destaca la evolución y el reconocimiento social alcanzado por la educación física a través de su historia. Para Cagigal (1957), por ejemplo, ha de abarcar todo lo que pueda ser reconocido como educativo dentro de los ejercicios físicos. En la definición de lo físico encontramos conceptos de gran utilidad actual: en primer lugar, el valor de lo corporal y el cuerpo; en segundo lugar, el movimiento como elemento clave. El componente que se va a mantener hasta nuestros días es precisamente lo físico, lo corporal, el movimiento, y no el de la educación.

Actualmente se reconoce la necesidad de lograr ambientes y condiciones que generen bienestar y una mejor calidad de vida en las personas como respuesta al incremento significativo de las enfermedades crónicas no trasmisibles, provocadas en un alto porcentaje por el sedentarismo. Eso contribuye a la redefinición del concepto y los alcances de la educación física, permitiéndole trascender al ámbito de la salud para ser considerada como el área encargada de fomentar, a través del movimiento, una vida saludable.

En este mismo sentido, se considera como uno de los principales propósitos de la educación física la búsqueda de la conservación y el 
desarrollo de la salud debido a que ayuda al ser humano a mejorar sus potencialidades tanto biológicas y físicas como sicológicas y sociales.

Al parecer existe un consenso en que la educación física estimula ciertos aprendizajes que afectan a la totalidad del ser. Falta definir cuál es la naturaleza de dichos aprendizajes y la forma en que se incorporan e influyen en la conducta humana (Romero y Amador, 2007).

\section{Finalidad de la clase de Educación Física para escolares colombianos}

El estudio determinó dentro de su espectro de análisis la identificación de lo que esperan niños y jóvenes de la clase de Educación Física. En este sentido, se buscó identificar el interés de los escolares en esa clase como un elemento vinculado a la formación que se desarrolla dentro del currículo de colegios y escuelas. Algunos estudios que se usaron como referencia para la investigación se orientaron a identificar esos intereses y actitudes: Casimiro (1999); García Montes (1997); Moreno-Murcia, González, Hellín y Martínez (2011); Sánchez (1996) y Torre (1998).

Para establecer la finalidad de las clases de educación física según los escolares colombianos se plantearon varias preguntas. La primera de estas permitía a los estudiantes escoger un máximo de dos alternativas de respuesta. Se encontró que el $50.52 \%$ de la muestra considera que la finalidad de las clases de Educación Física en su institución debe ser la de desarrollar actitudes y sensibilidad hacia las prácticas de educación física sistemática para una vida sana y saludable.

$\mathrm{Al}$ seleccionar la respuesta complementaria para esta pregunta el $18 \%$ de la muestra optó por la opción dos. Es decir, que además de lo anterior las clases de Educación Física tienen por objeto garantizar en el individuo y en la comunidad el conocimiento y práctica del deporte, la recreación y el aprovechamiento del tiempo libre.

Sobre este mismo ítem un $12.8 \%$ de la muestra considera que en la clase de Educación Física se pueden adquirir conocimientos y capacidades de aprendizaje que permitan la correcta utilización del tiempo libre a través de toda la vida. 
Además de indagar por los fines que deben tener las clases de Educación Física, también se consultó a los jóvenes sobre los contenidos que consideran pertinentes. En este sentido, del total de encuestados el $77 \%$ considera necesario que todas las actividades físicas se tengan en cuenta para las clases y solo el $9.3 \%$ indica que habría que reservar el nombre de deporte para las actividades de competencia.

Lo anterior refleja una tendencia de los escolares a reconocer la educación física como el área que favorece la inclusión de diversas manifestaciones motrices, las cuales son el medio para promover estilos y hábitos de vida saludable orientados a mejorar la calidad de vida de las personas.

En el desarrollo del estudio se pudo determinar que las actividades que más agradan a los jóvenes entre las realizadas en la clase de Educación Física son la práctica de un deporte, con un $48.1 \%$, seguida de ejercicios físicos, con un $17 \%$, y el desarrollo de juegos en un contexto recreativo, con un $16 \%$. En menor porcentaje, pero significativo, se encuentran las actividades recreativas diferentes al juego, con el $13 \%$.

La totalidad de los encuestados reconoce agrado por la práctica de un deporte, por encima del ejercicio físico, los juegos y las actividades recreativas, en ese orden. Esto implica que en todos los rangos de edad y en ambos géneros se siente mayor interés por la práctica de un deporte específico que por la actividad física en general. Puede ser el resultado, entre otros aspectos, de los programas que vienen impulsando el Ministerio de Educación Nacional, Coldeportes y los establecimientos educativos para promover la participación de los estudiantes en eventos deportivos de los ámbitos local, regional y nacional. 
Figura 6. Representación porcentual sexo vs. agrado (ítem 1)

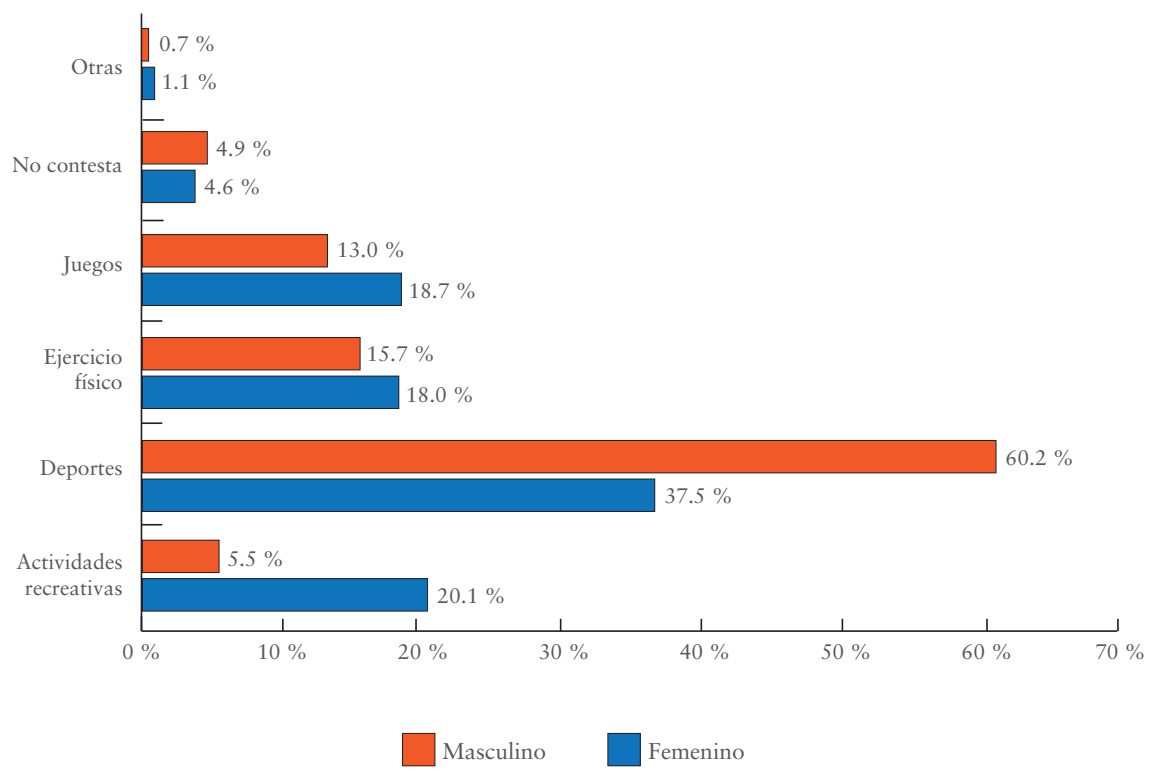

En la figura 6 se evidencia que la preferencia hacia la práctica de los deportes es del $60 \%$ entre los encuestados de género masculino y de $38 \%$ entre los encuestados de géner femenino. Es importante resaltar que las mujeres tienen alta predilección por las actividades recreativas y el juego, sumados $39 \%$, mientras que esa misma tendencia entre los varones apenas alcanza el $18.5 \%$. Por otra parte, existe un porcentaje representativo que aún no manifiesta con claridad sus preferencias en términos de actividades fisicodeportivas.

El estudio realizado por Romero y Amador (2007, p. 139) con jóvenes universitarios respalda la importancia que los estudiantes dan al deporte en Colombia:

Si bien es cierto que la publicidad que posee el deporte de rendimiento es considerablemente superior a la destinada para el fomento del deporte para todos, el deporte formativo o el deporte para la salud; queremos señalar que durante los últimos años se han establecido una serie de programas y proyectos que incentivan a la práctica regular de la actividad física, principalmente con fines de salud. En este sentido, un $97.6 \%$ de los estudiantes manifestaron 
que en Colombia se otorga al deporte un lugar muy importante. Es decir, que el reconocimiento social del sector se encuentra en un nivel alto. Por el contrario, sólo el $1.3 \%$ consideraron que el deporte tiene poco o nada de importancia para el país.

De igual manera, la mayoría absoluta $(78.23 \%)$ de los sujetos de género femenino (841) afirman que todas las actividades físicas deben considerarse parte de la clase de Educación Física, mientras el $74.94 \%$ de los sujetos encuestados de género masculino coinciden con esa apreciación.

Figura 7. Actividades físicas en la clase de Educación Física

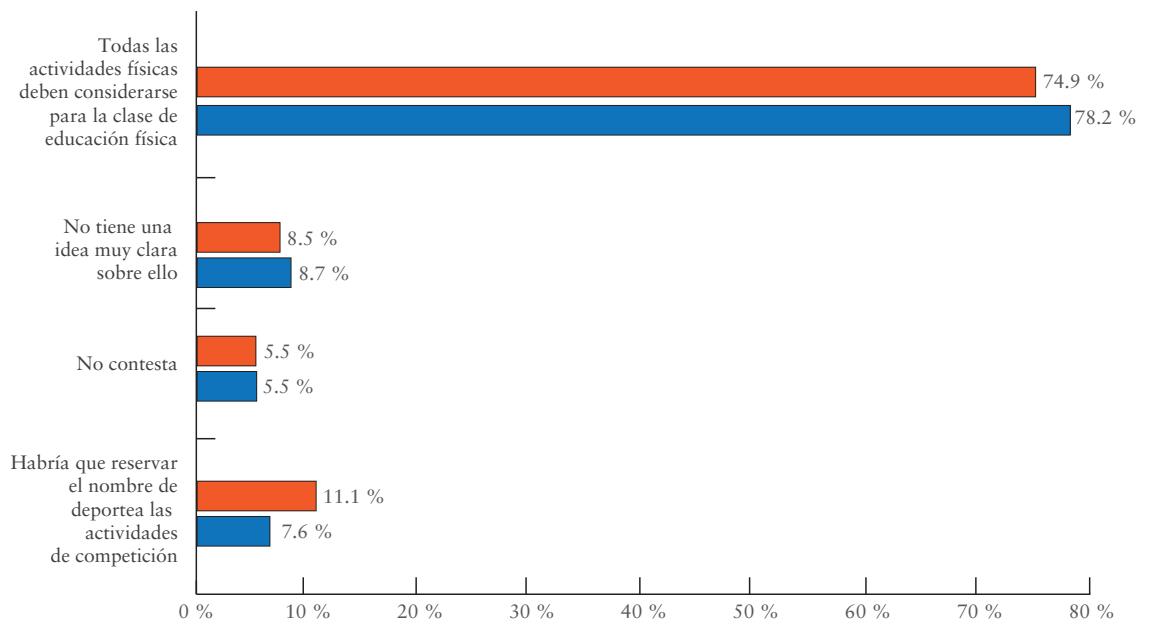

Los deportes son algunos de los medios utilizados en las clases de Educación Física para lograr los fines de formación establecidos de acuerdo a cada edad escolar. En este contexto se evidenció que el $62.1 \%$ de los encuestados desearía que se incluyera en su clase el deporte de la natación con una frecuencia de una a dos veces por semana $(21.9 \%)$ y que el $17.7 \%$ le daría continuidad a esta actividad deportiva fuera del calendario escolar. En segundo lugar, se observó que un 55.57 desearía que se incluyera el fútbol con una frecuencia de práctica de tres a más veces por semana $(20.1 \%)$. Es importante señalar que de acuerdo con la normativa que rige a las instituciones de 
educación pública los rectores de los colegios tienen la potestad para establecer la intensidad semanal de la clase de Educación Física mediante los acuerdos emanados por el Consejo Académico de la Institución atendiendo a su Proyecto Educativo Institucional. De igual manera, en Colombia las instituciones educativas deben establecer seis proyectos transversales de obligatorio cumplimiento. Uno de ellos corresponde al programa de hábitos y estilos de vida saludables. Lamentablemente la mayoría de los colegios que participaron en el estudio tan solo destinan dos horas a la semana para la clase de Educación Física en cada uno de los grados de escolaridad y no se identificó la aplicación del proyecto transversal correspondiente.

Otra disciplina de interés para los jóvenes en la clase de Educación Física es el voleibol: $65 \%$ de encuestados así lo consideraron y el $16.3 \%$ lo practicaría con una frecuencia de actividad de una a dos veces por semana. Además, el $10.1 \%$ del total de respuestas le daría continuidad tanto en actividades extracurriculares como en periodos vacacionales.

Los menores también consideraron importante la inclusión del baloncesto con el $16.5 \%$ de frecuencia de práctica deseada de una a dos veces por semana. 
PrÁCtICAS Fisicodeportivas: ACTITUd E INTERÉS DE ESCOLARES COLOMBIANOS
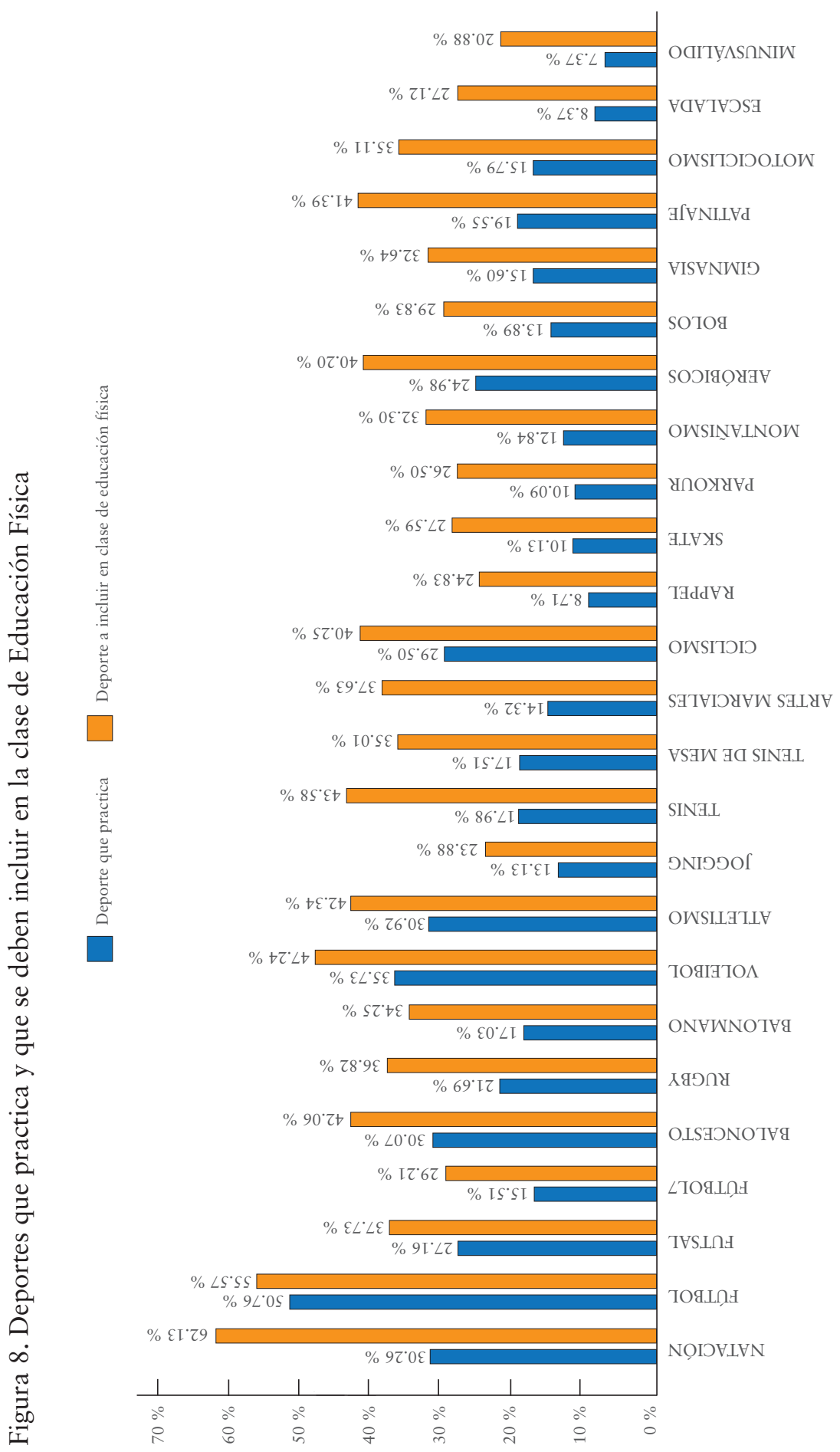


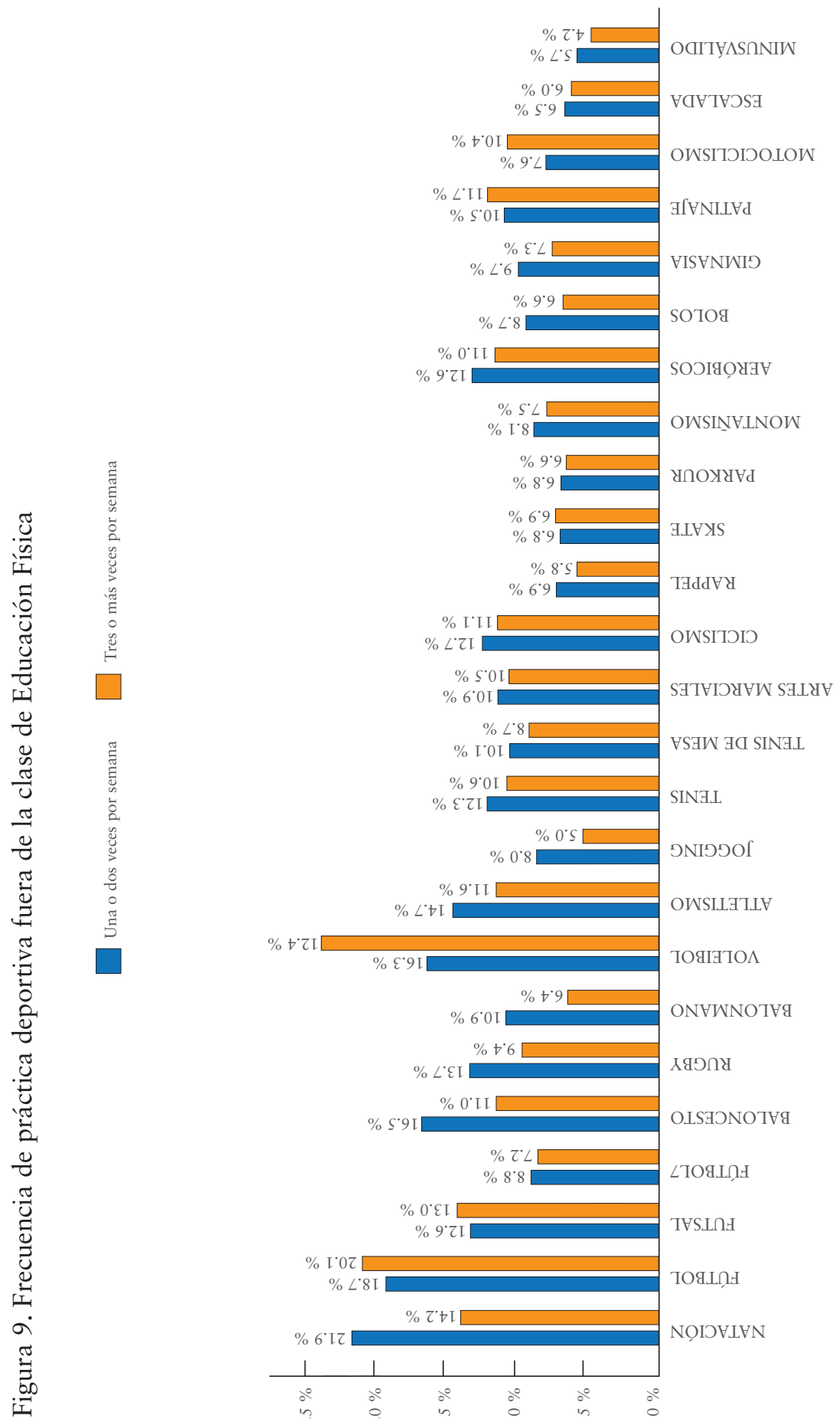




\section{La recreación en la clase de Educación Física}

\section{Sobre los conceptos de recreación, lúdica y aprovechamiento del tiempo libre}

En la sociedad actual la reducción del espacio y el tiempo libre corresponde a una realidad innegable. El hombre ha fundado su éxito en la convivencia social, pero actualmente se enfrenta a una realidad enajenada por el aumento del tiempo de trabajo y, con ello, la menor calidad y cantidad de tiempo dedicado a las relaciones con los demás. En este sentido, el tiempo consagrado por los padres a sus hijos es cada vez menor, lo que ha provocado cambios importantes en los comportamientos de las relaciones básicas de las familias.

La ONU en diversas publicaciones ha enunciado que es función del Estado defender la familia. Por lo tanto se deben establecer estrategias que incluyan el reconocimiento del tiempo libre, la recreación y el deporte como medios de unidad integral e integradora que promueven el desarrollo intelectual, emocional, físico y sicológico del individuo.

Podemos identificar la recreación desde dos puntos de vista: como necesidad y como derecho fundamental. Al seguir profundizando en el análisis encontramos que va mucho más allá de la alegría que se transmite al desarrollar actividades en las que prima la diversión. Su verdadera esencia es ofrecer la oportunidad de construcción del sujeto desde su libertad. Si esto no sucede, las actividades organizadas como recreativas simplemente corresponderán a eventos diseñados para pasar el tiempo, que ni educan ni trasforman al ser humano en sus valores más esenciales.

Por lo tanto, la recreación es considerada una forma de bienestar individual y social que contribuye a mejorar la calidad de vida de cada sujeto mediante el uso adecuado del tiempo libre y la mejora de su autoconcepto, su autoestima, su conocimiento de sí mismo, su relación con el otro y su interacción social.

Según lo expuesto por Sajón (citado en Ramos, 1986, p. 23), la recreación es el conjunto de 
experiencias humanas, cuya vivencia hace posible la satisfacción, es una dimensión superior y permanente de las necesidades de manifestación plena y armoniosa de su ser biológico, psicosocial y cultural, a la vez que contribuye a su educación permanente e integral, a su descanso dinámico y renovador de energías físicas, intelectuales y espirituales; y al fortalecimiento y desarrollo de su integración exitosa, solidaria, creadora y transformadora de la vida de su comunidad y de la sociedad.

La relevancia de la recreación para el desarrollo integral del ser humano es innegable, no solo en el sentido individual, sino en el social. Por eso un programa al respecto estructurado correctamente permitirá el desarrollo de una comunidad específica. Como lo afirma Osorio (2005), a través de la recreación

se propician dinámicas de mejoramiento y autodependencia de las comunidades a partir de los beneficios, garantizados en la calidad de la vivencia recreativa, con respeto a su dimensión humana esencial: la lúdica, las actitudes y la libertad de elección por parte de quien se recrea.

Se suele confundir la recreación propiamente dicha con las actividades recreativas. En este sentido, la recreación busca el desarrollo holístico del sujeto mediante la participación activa en su construcción y en su ejercicio de libertad. Por otra parte, las actividades recreativas son el apoyo para garantizar el afloramiento de la condición lúdica del ser humano, inhibida muchas veces por las 'normas socialmente aceptadas. Uno de los principales objetivos de las actividades recreativas es lograr que los individuos fortalezcan sus propios valores.

Las actividades recreativas ofrecen a cada ser humano diferentes formas de reconocer su entorno, lo que brinda la posibilidad de expresar múltiples sentimientos y percibir sensaciones en las cuales se particularizan distintas reacciones emocionales. 
Figura 10. Características de las actividades recreativas y la recreación

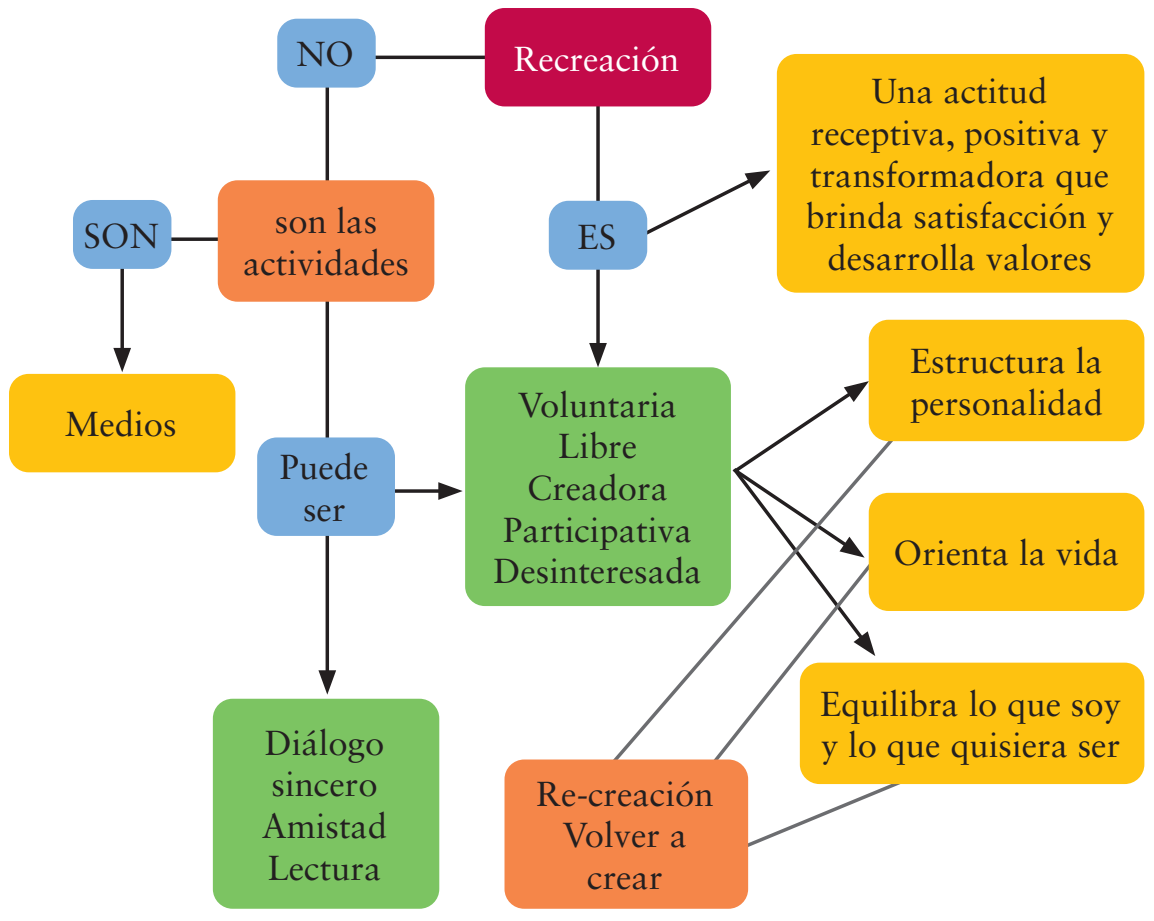

La recreación cobra importancia al ser entendida como un proceso en el cual el ser humano se trasforma, se renueva y cambia sus comportamientos mediante el desenvolvimiento placentero en su tiempo libre. Además, logra satisfacer los deseos de descanso, entretenimiento, expresión, aventura y socialización mediante las interacciones sociales y genera manifestaciones de afecto, cariño, comprensión y aceptación. Todo eso motiva la aparición de prácticas sistemáticas y adecuadas de recreación.

En cuanto a la lúdica, es considerada como la capacidad del ser humano para percibir y expresar sus emociones. Esta condición es única y se encuentra predispuesta genética e inherentemente en cada individuo. Permite expresar el potencial creativo propio, en especial mediante el juego, pero también en todas las otras actividades humanas. 
Figura 11. Diferencia entre juego y lúdica

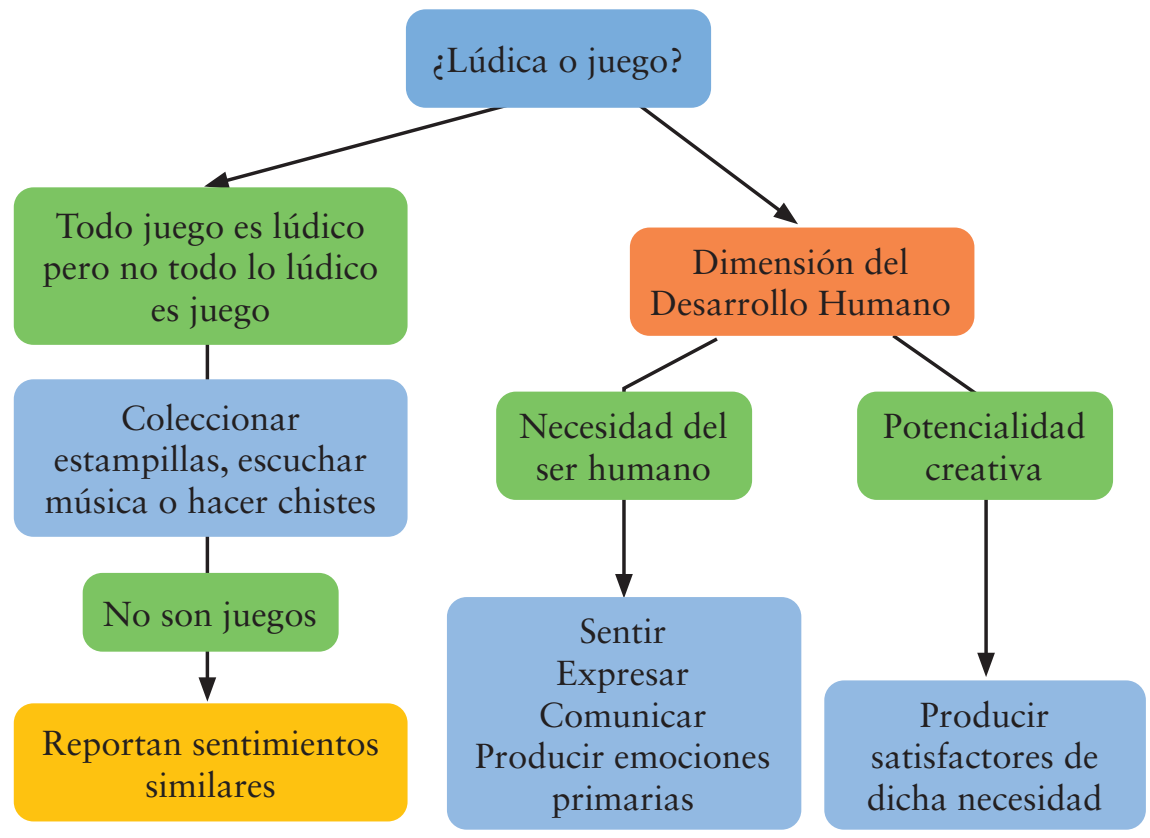

El juego es una forma de expresión lúdica. Puede desarrollarse a través de estructuras sencillas de participación e integración social, con variedad de propósitos, que van desde la enseñanza de una habilidad motora o la apropiación de un aprendizaje hasta el desarrollo de habilidades sociales o la construcción de valores.

El juego se considera la actividad central del niño y su máximo escenario de exploración. Una experiencia muy intensa física, social, afectiva y espiritualmente, que genera diferentes estados de satisfacción e interiorización y variedad de oportunidades para la introspección.

La incorporación del juego en las clases de Educación Física ha sido muy estudiada y ha cobrado gran relevancia su potencial para desarrollar la creatividad. En este sentido, es el maestro el que da cabida a sus funciones al permitir un desarrollo del juego de manera diversa, de tal manera que los escolares tengan que resolver situaciones-problema con un grado muy elevado de variabilidad (Cecchini et al., 2012). 
El tiempo libre es una construcción social en la que el individuo —de acuerdo a su percepción de la realidad, formación y estructuras sociales en las que se desenvuelve- evidencia el valor que asigna a acciones distintas al trabajo o el cumplimiento de obligaciones no remuneradas — acompañar a los hijos, atender las compras del hogar, desarrollar tareas domésticas, entre otras-, como el desarrollo de procesos de compensación sicológica y fisiológica.

El valor dado por lo general se puede estimar en horas, semanas o calidad de tiempo disponible. Se considera además que para que sea tiempo libre debe ser dedicado a actividades de descanso y desarrollo personal, y en todo caso no a actividades que empobrezcan la condición humana o en las que el individuo sea manipulado de modo que no pueda elegir libremente el desarrollo y contenido con el que llena ese espacio social.

Aunque los escolares no cuentan con un trabajo remunerado, sí realizan actividades obligatorias, como asistir a clases en una institución educativa, ayudar con las tareas del hogar o hacer los deberes escolares. También tienen para sí un tiempo liberado de obligaciones, que no siempre es de libre elección pues dependerá en gran parte de la discrecionalidad y disponibilidad de los padres y las condiciones del medio que los rodea.

Así, si un niño, después de haber cumplido con la obligación de asistir al centro escolar, llega a su casa y cumple sus demás obligaciones, dispone de horas libres. El uso de este tiempo se supeditará a las actividades que sus padres le permitan. Si es el niño el que escoge libremente la actividad de acuerdo a su preferencia, se puede entender que la actividad se da en el marco del uso de un tiempo libre; si por el contrario la actividad corresponde a lo que los padres permitan o quieran que su hijo acceda, no corresponderá al desarrollo de tiempo libre, sino, por el contrario, a un tiempo ocupado con una actividad diferente a la escolar.

En este mismo sentido, el escolar puede tener un tiempo en el que desarrolla actividades con roles solo de consumo - por ejemplo, dedicarse a hacer zapping (dejarse llevar de un programa de TV a otro)-. Este periodo implica una sensación de aburrimiento, de modo que no puede dársele el valor de tiempo libre propiamente dicho. 


\section{Manifestaciones de la recreación presentes en la clase de Educación Física}

De acuerdo con las respuestas se evidenció que los docentes encargados de orientar la clase de Educación Física desarrollan actividades recreativas ligadas al deporte: $61.3 \%$ del total de encuestados lo confirman. Se observa además que un $19.27 \%$ de los docentes están aplicando estrategias para la conservación y preservación del ambiente - la Educación Física es una asignatura con todas las características que permitirían reconocer el valor y el mejoramiento del sistema ambiental por parte de los escolares-. No obstante, contrasta este interés con la baja inclusión de importantes actividades, como el ecoturismo y la recreación turística, según un $2.85 \%$ y un $3.28 \%$ de los encuestados respectivamente.

\section{Manifestaciones recreativas a incluir en la clase de Educación Física}

Al comparar las figuras 12 y 13 sobre las tendencias recreativas desarrolladas en la clase de Educación Física y las que los estudiantes desean incluir (respectivamente), se confirma un marcado interés por la recreación deportiva. No obstante, también se evidencia un mayor interés de los estudiantes por las actividades relacionadas con el ecoturismo, con una variación del $15.51 \%$ entre la realidad actual y la preferencia. Algo parecido ocurre con la recreación turística, cuya variación asciende a un $15.13 \%$. Otro aspecto importante a considerar es la tendencia de los escolares a favorecer la recreación terapéutica (variación de $9.8 \%$ ). Es importante resaltar que se mantiene la tendencia favorable a la recreación ambiental, lo cual representa una alta fortaleza para la generación de estrategias de formación y consolidación de ciudadanos responsables con el medio ambiente.

Es necesario señalar que del total de encuestados el $1 \%$ señaló la opción de otras tendencias específicamente refiriéndose a la práctica de los deportes extremos. 
Figura 12. Actividades recreativas desarrolladas en la clase de Educación Física

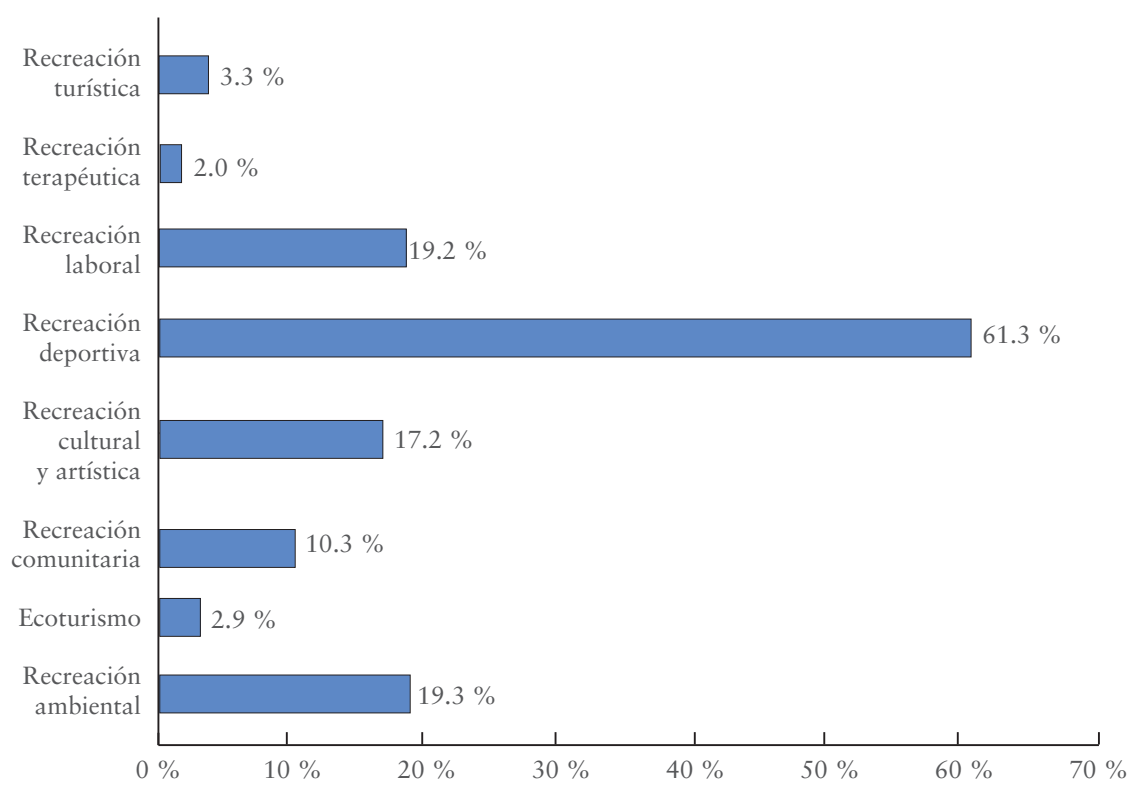

Figura 13. Manifestaciones recreativas a incluir en la clase de Educación Física

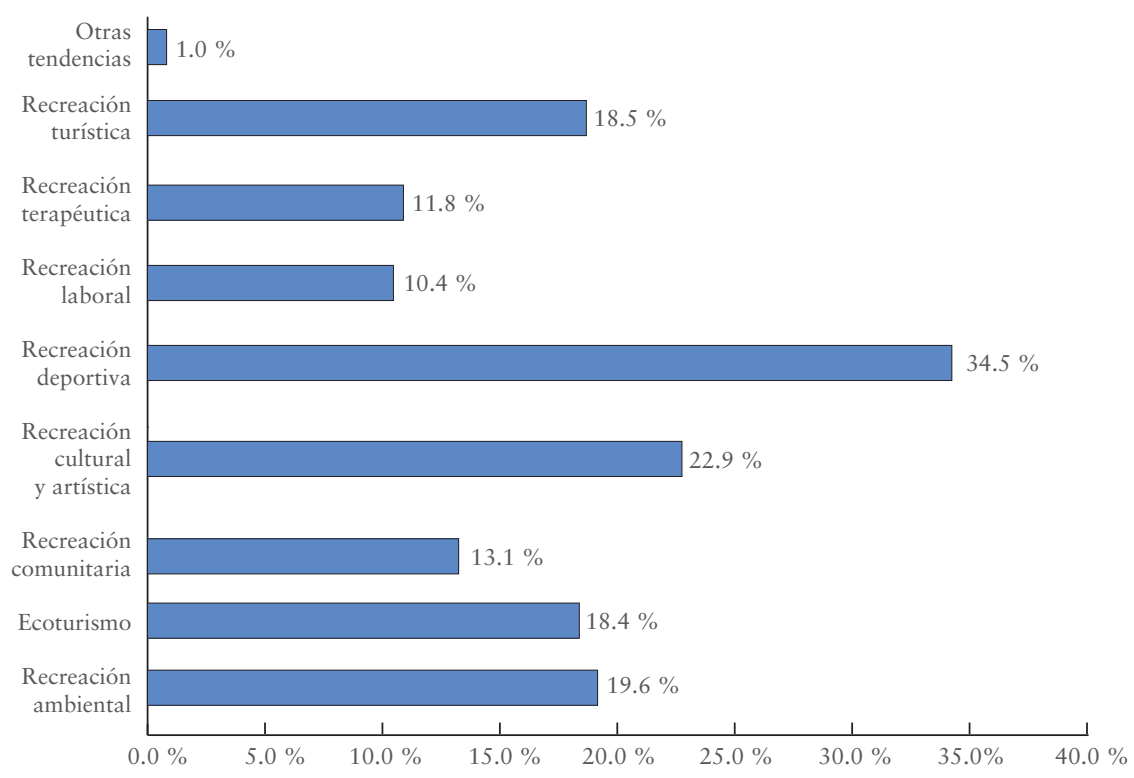




\section{Interés hacia las prácticas fisicodeportivas}

\section{Importancia social de la práctica fisicodeportiva}

La importancia de la práctica fisicodeportiva en la era moderna es señalada por Rousseau (1792) en su obra Emilio o de la educación. En esta deja ver cómo a través del desarrollo de los ejercicios físicos se fortalecen el cuerpo y el alma de un joven huérfano. De igual manera, Kant (1803) en su Pedagogía desarrolla un capítulo sobre la importancia de la educación física en la formación del ser humano.

Es en realidad hacia finales del siglo XIX que la práctica de actividades fisicodeportivas empieza a ser socialmente impulsada por personajes como el barón De Coubertin, creador de los Juegos Olímpicos modernos. De igual manera, Cureton (1964), destaca el carácter moral de los aspectos del trance deportivo sobre la base de la iniciativa, la perseverancia, la intensidad, la búsqueda del perfeccionamiento y el menosprecio del peligro.

A mediados del siglo xx se empezó a considerar al deporte como un área de conocimiento específica. Sin embargo, Werner (1994) ratifica que en Latinoamérica esta tendencia no se desarrolló. Por el contrario, aquí la práctica de las actividades fisicodeportivas se limitaba al "ejercicio reproductivo de técnicas y procedimientos, carentes de fundamento y alejado de los debates e intereses teóricos".

La proclamación de la Carta Internacional de la Educación Física y el Deporte (Unesco, 1978), que incluye con gran fuerza esta área en los procesos educativos formales, logra un gran impacto en la promoción del deporte como parte del desarrollo humano y social.

Sin embargo, el impacto social esperado tomó un rumbo diferente. Lo podemos apreciar en los planteamientos de Cagigal (1975), quien manifiesta que la enseñanza de la educación física, al tener como herramienta de trabajo los deportes, adoptará las prácticas de aprendizaje propias de la competición más que las de la práctica habitual.

Así pues, al consolidarse el deporte de rendimiento como tendencia de unos pocos, se deja de lado la práctica de este como forma de actividad física. Sin embargo, con la aparición de gran cantidad de enfermedades no trasmisibles a causa del sedentarismo, la importancia social de la actividad física y las prácticas deportivas con 
miras al mejoramiento del bienestar y la salud, ocupa los primeros lugares de interés.

En este contexto se han establecido diferentes documentos, estrategias y movimientos, entre los que se destaca el Manifiesto de São Paulo para la Promoción de la Actividad Física en las Américas (2000). En este documento se refleja la necesidad de que los países generen espacios políticos y sociales que fomenten la vinculación de la actividad física habitual a los estilos de vida de la población.

\section{Motivos por los que escolares colombianos realizan actividades fisicodeportivas}

Los motivos por los cuales los escolares colombianos practican actividades fisicodeportivas de forma regular son variados: abarcan diversas mejoras a nivel físico, síquico y social como aporte para la calidad de vida (Martínez Gómez et al., 2009). Sin embargo, como se ha demostrado, existe un desinterés generalizado entre los jóvenes por el desarrollo de prácticas deportivas. Las investigaciones sobre este fenómeno sugieren que una de las razones por las cuales los escolares no se adhieren a programas de ejercicio físico, no practican constantemente un deporte o lo abandonan de forma prematura tienen que ver con la programación y el diseño de la práctica fisicodeportiva que no parecen responder a las demandas de dicho grupo poblacional (Utter et al., 2006).

En este sentido, considerando una sola opción de respuesta de manera categórica, una de las preguntas realizadas a los escolares en el estudio indagó sobre aquellos elementos que les interesaban y que podrían utilizarse para promover la práctica de la actividad fisicodeportiva. Del total de los 2102 escolares que participaron en el estudio, un 80.69 \% manifestó que lo que más llama la atención de las actividades fisicodeportivas es que permiten adquirir una buena forma física; la segunda opción más seleccionada es que brindan un ambiente de diversión y entretenimiento $(32.7 \%)$; la tercera, que permiten estar con amigos $(20 \%)$. 
Figura 14. Motivos por los que se dan las prácticas fisicodeportivas

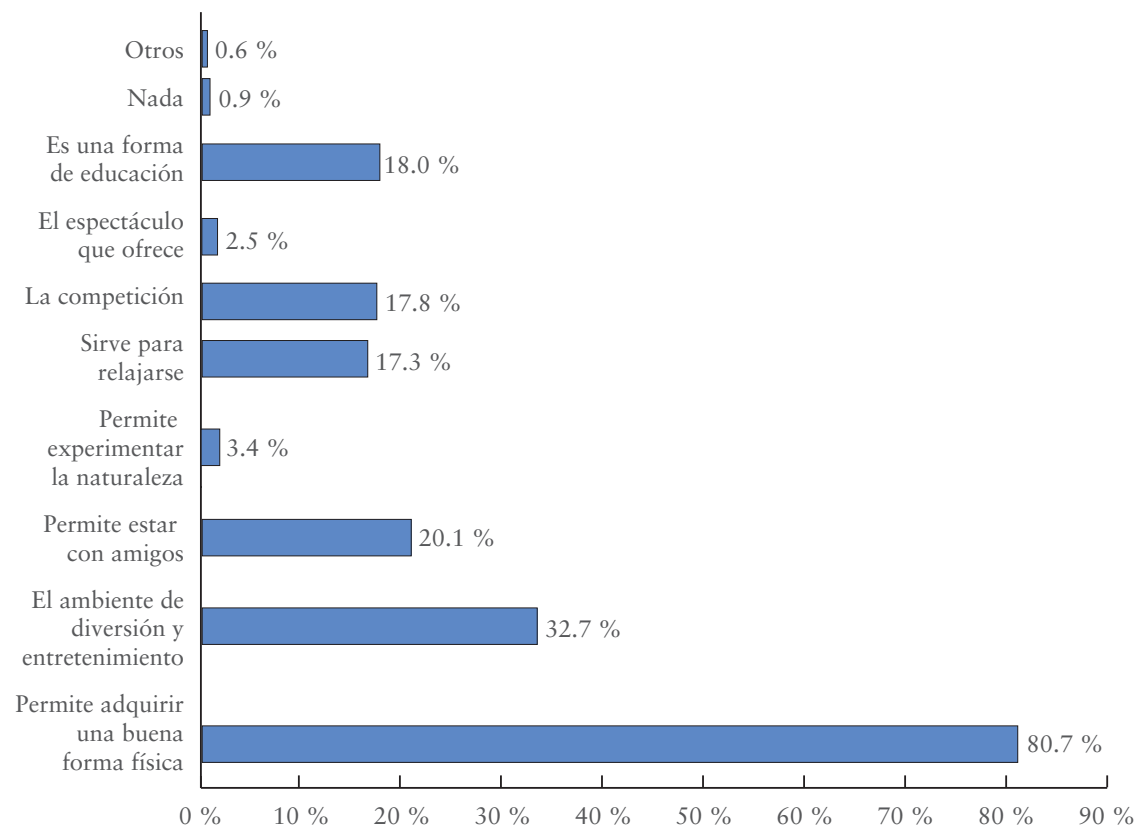

Estos resultados son relevantes si los comparamos con los estudios realizados en adolescentes españoles por Martinez Baena (2012b), en los que el orden de los motivos para realizar ejercicio físico es el siguiente: a) por diversión, b) por la posibilidad de estar con los amigos y c) por el gusto hacia la práctica. Estos datos fueron constatados por Utter et al. (2006) y García-Ferrando (2006). Mientras tanto, en el estudio realizado por Guillén et al. (2005) con niños y adolescentes brasileños se detectó que los principales motivos de participación eran estar alegres y divertirse.

Se resalta entonces el hallazgo de que la motivación de los jóvenes se centra en encontrar o adquirir una buena forma física. Este elemento fue ratificado cuando se indagó el porqué de las preferencias en cuanto a las prácticas de los ejercicios físicos. Se podían escoger dos respuestas, y así fue como se destacó la dupla en la que la práctica fisicodeportiva permite adquirir una buena forma física y disfrutar un ambiente de diversión y entretenimiento. 
Romero y Amador (2007), por su parte, afirman que a través de la práctica deportiva los estudiantes buscan buena forma física, diversión, entretenimiento, relacionarse con los demás, disfrutar de la naturaleza, educarse y especialmente mejorar la salud, sin importar la competición y el enfrentamiento.

Dishman et al. (2005) explica que los hombres optan más por hacer ejercicio físico para pasar el rato con los amigos, mientras que las mujeres lo hacen simplemente por gusto. Respecto a lo primero existe una amplia evidencia de que las interacciones con los compañeros resultan ser un elemento enormemente motivador para los individuos (Haverly y Davison, 2005). Además, se confirma una mayor tendencia (aunque en porcentajes pequeños) de las mujeres hacia una práctica para mantener la línea y mejorar la salud, y de los hombres hacia una práctica competitiva.

De esta forma, en consonancia con Malina (2001) y Otero (2004), se podría afirmar que las diferencias significativas en cuanto a género consisten en que las mujeres conceden más importancia al hecho de cuidar la estética corporal y la salud que los hombres, y que estos en cambio atribuyen una mayor importancia a la competición y a estar con los amigos.

Desde nuestra óptica, resulta importante insistir en la adquisición de una mayor dotación de recursos por parte de las administraciones públicas, con el fin de promover estrategias de intervención de actividad fisicodeportiva más cercanas a las expectativas, los intereses y las demandas sociales. Eso propiciaría una mayor participación de niños y jóvenes en las actividades fisicodeportivas, así como la adquisición de estilos y hábitos de vida más saludables en el futuro.

\section{Valor que tiene la práctica fisicodeportiva en escolares colombianos}

Del total de encuestados el $77.64 \%$ se manifiesta muy de acuerdo con que hacer deporte permite estar en forma y saludable. Aunado a ello, el $19.55 \%$ está bastante de acuerdo con la aseveración descrita, lo cual eleva su aprobación hasta aproximadamente el $97 \%$. Este valor denota la congruencia de las respuestas si se lo relaciona con el asunto de la preferencia (ítem 3): $81 \%$ afirma que el deporte 
y las actividades físicas y recreativas permiten mantener el cuerpo y la mente saludables.

Con respecto a considerar el deporte como un escape para liberar saludablemente la agresividad y el mal humor, el $25.69 \%$ señala estar muy de acuerdo, y un $35.97 \%$, bastante de acuerdo. Es necesario resaltar que el $26 \%$ manifiesta estar poco de acuerdo con dicha afirmación. No obstante, el estudio realizado por Romero y Amador (2007) constata que los estudiantes se interesan en hacer deporte para estar en forma como fuente de salud y como válvula de escape para liberar la agresividad y el mal humor. De cualquier modo, esto ratificó la inclinación a valorar la práctica deportiva en atención a los beneficios que ofrece, especialmente en todo lo relacionado con la salud física y mental.

Con relación a la alternativa presentada, según la cual las actividades fisicodeportivas permiten relacionarse con los demás y hacer amigos, el $45.05 \%$ y el $37.39 \%$ indicaron estar muy o bastante de acuerdo respectivamente. Se mantiene la correspondencia con la respuesta en la que los encuestados señalaron que el deporte permite estar con amigos $(82.08 \%)$.

El $81.64 \%$ de los estudiantes expresaron en sus respuestas estar muy o bastante de acuerdo con que las actividades fisicodeportivas coadyuvan al desarrollo integral de los adolescentes en cuanto minimizan los obstáculos de la vida y constituyen una estrategia para fortalecer la disciplina y su formación como ciudadanos y ciudadanas. De igual manera, se mantiene el patrón de respuestas al preguntar si "hacer deporte permite vivir más intensamente y ayuda a romper la monotonía de la vida cotidiana": un $39.25 \%$ estuvo muy de acuerdo y un $39.06 \%$ bastante de acuerdo con esta afirmación. No obstante, el $17 \%$ manifestó estar poco de acuerdo.

En cuanto al deporte como competencia se observa que un $26 \%$ manifiesta participar en una competencia sana con sus amigos con la finalidad de divertirse y un $20 \%$ participa en eventos deportivo de carácter institucional, es decir, organizados por su colegio. Esto obedece en parte a la implementación de programas promovidos por el Ministerio de Educación Nacional y Coldeportes que motivan la competición entre los estudiantes. De igual manera, un $33 \%$ del total de 
encuestados prefiere la práctica del deporte no en su faceta de alto rendimiento (competencia), sino como una vía de aprovechamiento del tiempo libre $(17 \%)$ o sin preocuparse por competir (16\%). Por otro lado, el $12.7 \%$ participa de manera activa en los eventos deportivos organizados en su localidad (municipio).

En este mismo sentido, el estudio realizado por Romero y Amador (2007) señala que los motivos más frecuentes de los estudiantes para practicar algún deporte son la diversión y ocupar el tiempo libre. Le siguen: mantener y mejorar la salud y hacer ejercicio físico. Se observa en las respuestas dadas una orientación hacia aquellas actividades deportivas que ofrecen placer y aporte en términos de salud, lo cual puede estar ligado directamente con la difusión de la asociación entre el deporte y esos temas. Se destaca que la competencia pasa a ocupar el último lugar, lo que muestra el escaso interés por las prácticas deportivas con altas exigencias en las que el objetivo es ganar por encima de cualquier otro aspecto. 


\section{Preferencia por programas deportivos}

En cuanto a la pregunta sobre la preferencia de los jóvenes por los programas deportivos se identificó que el $34.7 \%$ del total de encuestados manifestó que solamente ve algunos. En este sentido, un $23.7 \%$ expresó que fundamentalmente ve partidos de fútbol. Por otra parte, el $11.5 \%$ afirmó nunca ver programas deportivos.

Figura 15. Preferencia de programas deportivos

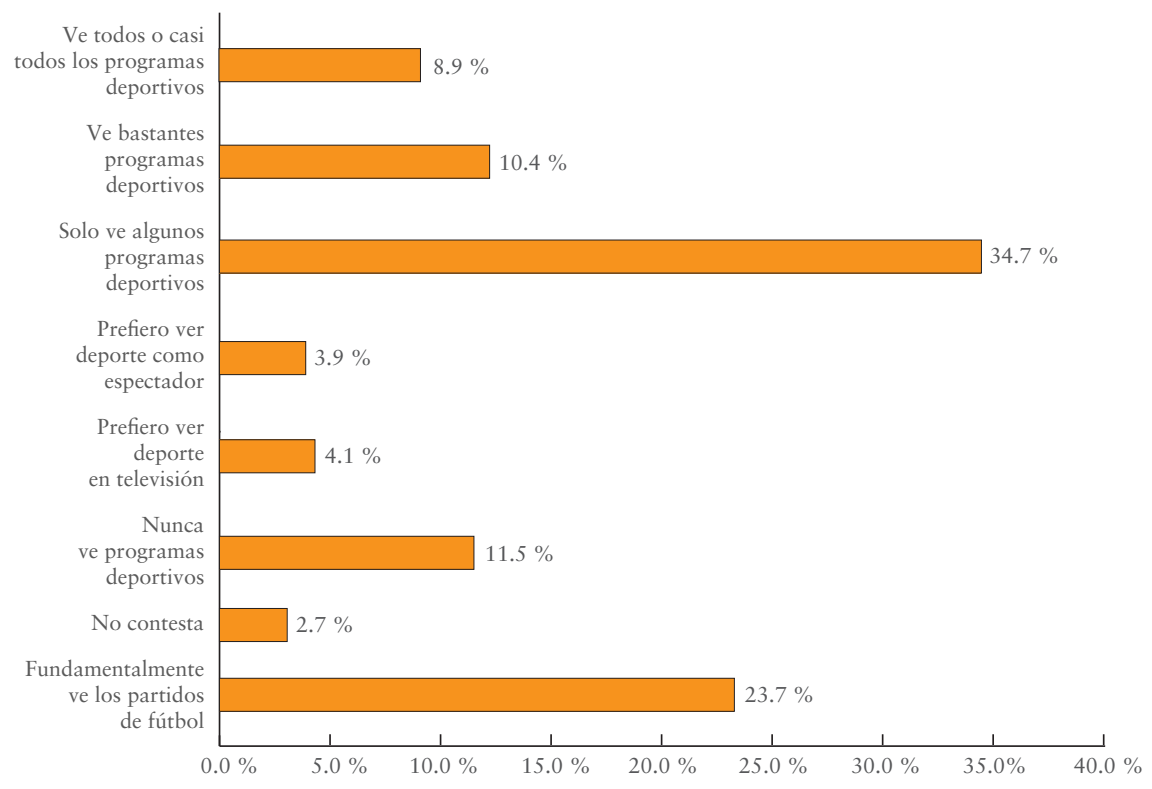




\section{Valoración del deporte como participación cívica}

En el análisis de los resultados de la encuesta nos encontramos con el fomento del deporte, de gran interés para la población bajo estudio, pues un $95 \%$ del total lo considera bueno y necesario para estimular buenos hábitos de participación ciudadana.

Figura 16. El deporte como promotor de la participación cívica

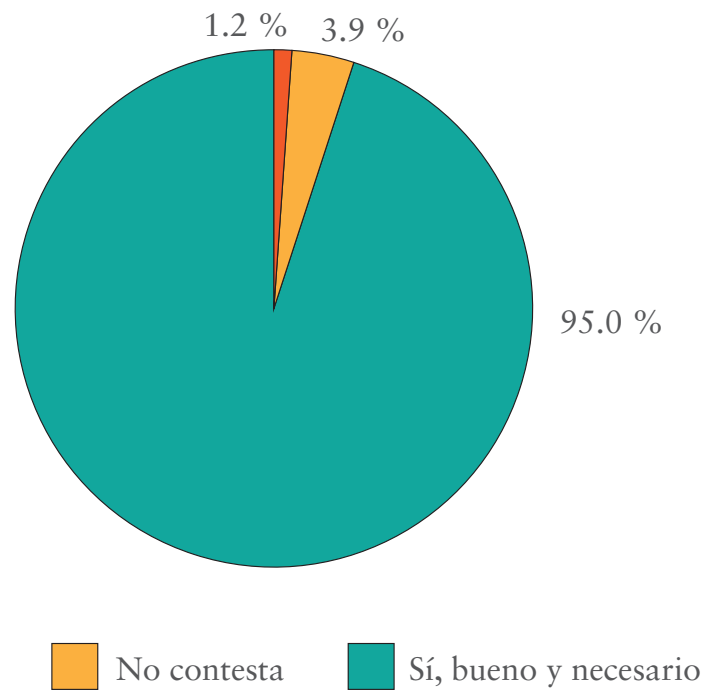

Los deportes como elementos centrales en la formación de los escolares

Uno de los objetivos fundamentales del estudio fue identificar la importancia de los deportes tradicionales para los jóvenes debido a que la vinculación de estos como contenido esencial en el desarrollo curricular de la educación física ha sido referenciada con gran interés (Delgado, citado en Poblete y Gamboa, 2013). Al analizar las diferentes respuestas de los jóvenes, los deportes que sobresalen son en primer lugar el fútbol, preferido por un $50.8 \%$ de los encuestados, con lo cual se identifica como la disciplina más practicada por los estudiantes colombianos; y en segundo lugar, con un $35.7 \%$, el voleibol. Esta tendencia es similar a la evidenciada en otros estudios 
según los cuales los docentes suelen invertir más tiempo enseñando deportes colectivos que cualquier otra actividad física a lo largo de la etapa escolar. Es decir, estos deportes (especialmente los de "invasión”) son los que ocupan mayor espacio dentro de los currículos de educación física escolar (Valera, Ureña, Ruiz y Alarcón, 2010; Robles, Giménez y Abad 2010).

En tercer lugar, con un $30.9 \%$, está el atletismo. Es importante resaltar que el baloncesto se encuentra en la cuarta posición de práctica, con un $30.1 \%$.

Finalmente, destaca también el reporte de práctica de deportes como la natación, el ciclismo y la actividad física de los aeróbicos, con $30.3 \%, 29.5 \%$ y $25 \%$, respectivamente.

Figura 17. Deportes más relevantes dentro del estudio

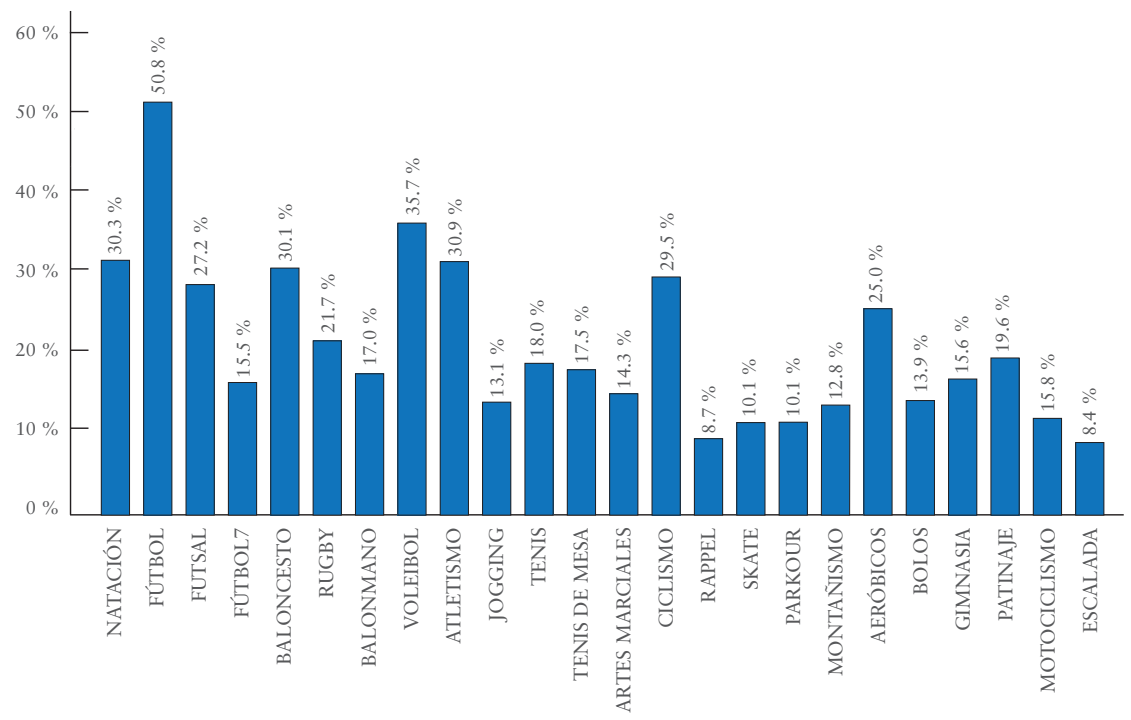

En el análisis realizado por regiones sobre las preferencias de los escolares con respecto a la práctica de las cuatro disciplinas deportivas principales según el estudio, se pudo evidenciar que los resultados están influenciados por el contexto cultural y diversos factores externos. De esta manera, en todas las regiones el deporte predominante es el fútbol, especialmente en la región pacífica. En efecto, su práctica es reportada allí por casi la mitad de los encuestados (49\%). 
Figura 18. Las prácticas deportivas más representativas por zona
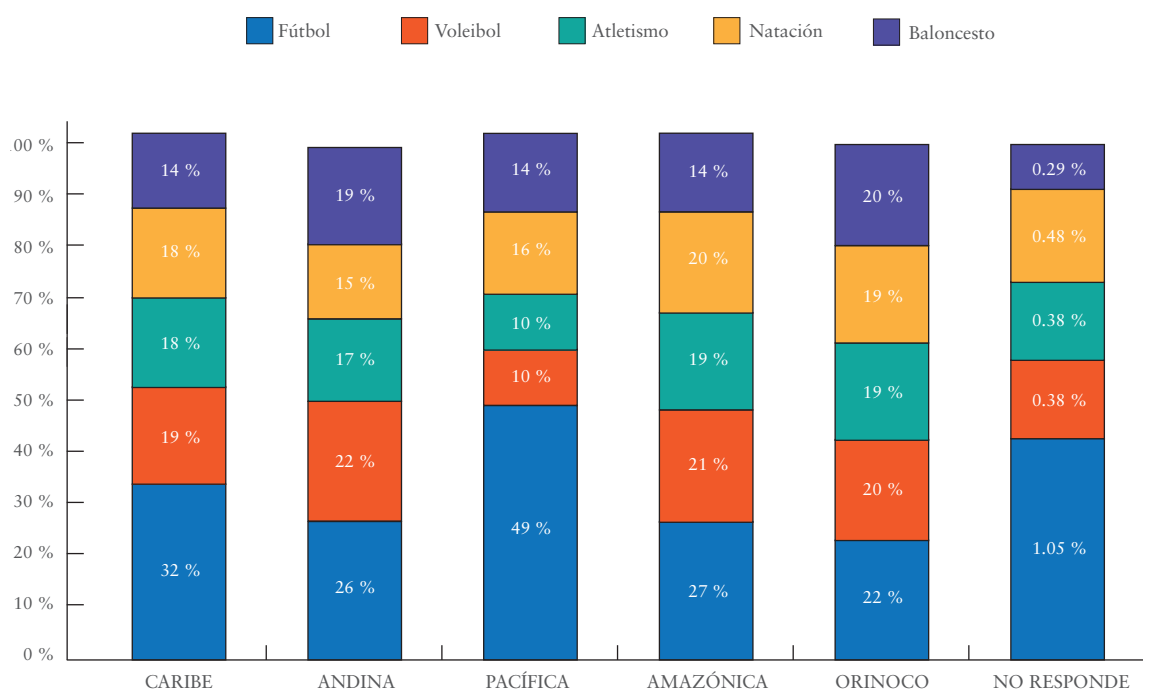

De los escolares que manifestaron practicar fútbol el $64.3 \%$ son del género masculino y un $34.3 \%$ del género femenino. El voleibol es el segundo deporte más practicado en todas las zonas, a excepción de la Pacífica, donde la práctica de la natación alcanza un $16 \%$.

El $80 \%$ de los encuestados que juegan fútbol considera que lo más atractivo de practicar una actividad deportiva es que los mantiene en buena forma física. Otro aspecto, considerado por un $31.14 \%$ de los futbolistas, es que genera un ambiente de diversión y entretenimiento, y un $23 \%$ indica que permite la competencia. Por otra parte, se observó que la mayoría de los hombres practica el fútbol, mientras que las mujeres se distribuyen entre el voleibol, el atletismo y el baloncesto. 
Figura 19. Práctica por género de cada disciplina deportiva

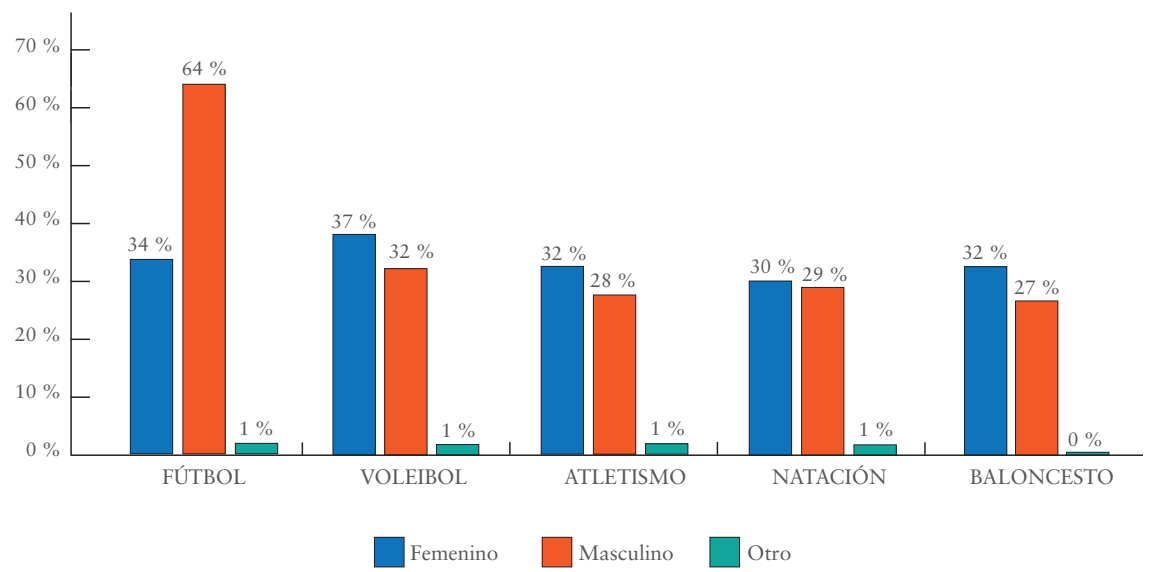

Figura 20. Agrado por el ejercicio físico, los juegos y otros deportes entre los practicantes de cada disciplina

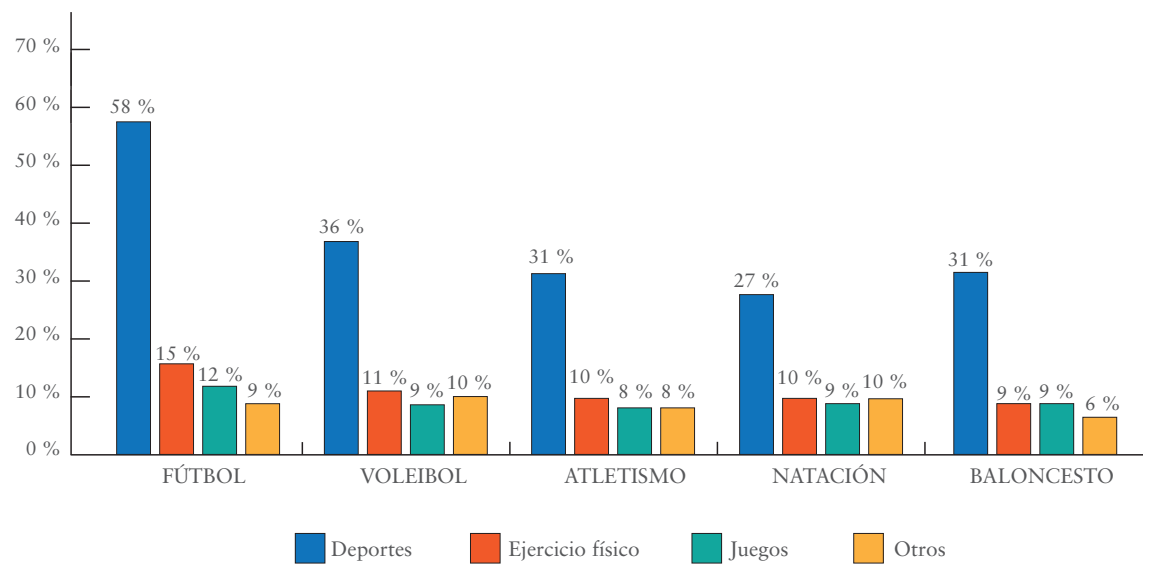

En cuanto al interés que tienen los escolares por el ejercicio físico y el juego como elementos complementarios de las disciplinas deportivas de su preferencia, se encontró que a quienes practican fútbol les agradan además otros deportes. En general, el ejercicio físico y los juegos continúan respectivamente en segundo y tercer lugar de preferencia entre los practicantes de cada deporte. 
Figura 21. Actitudes desarrolladas por los practicantes de fútbol

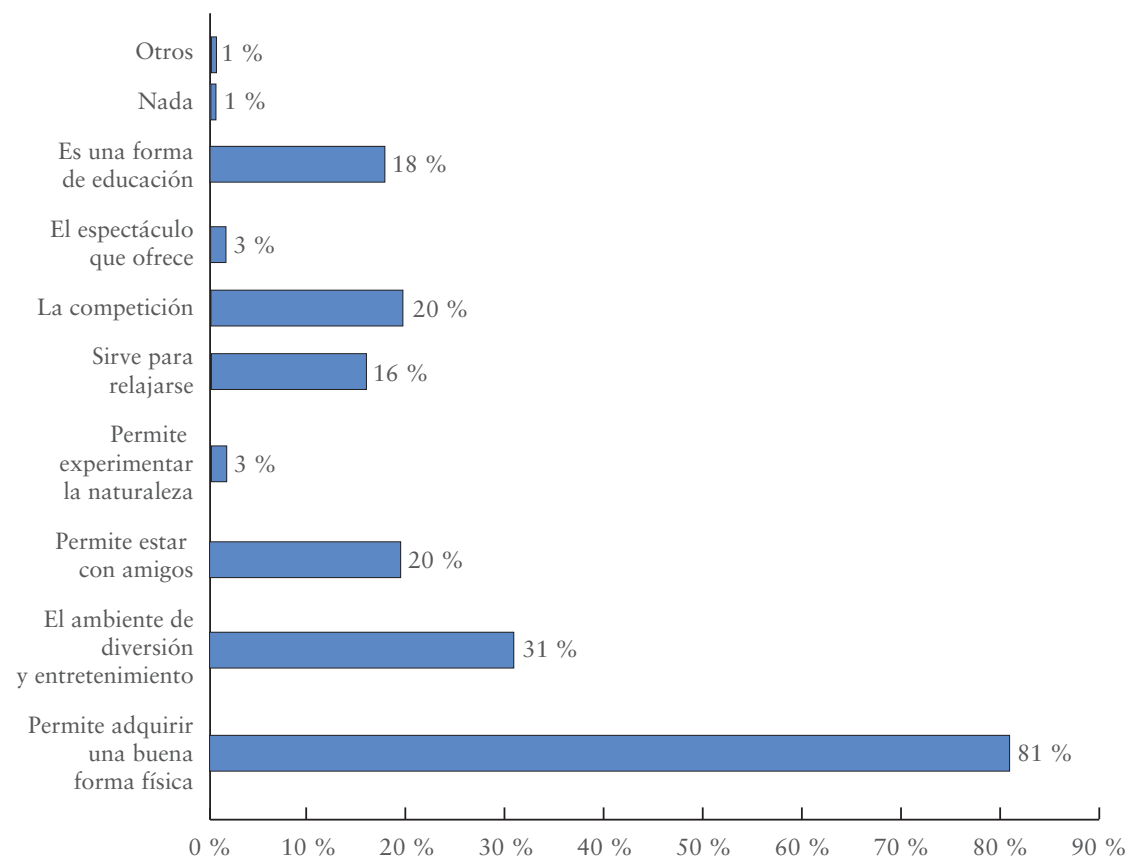

Figura 22. Actitudes desarrolladas por los practicantes de voleibol

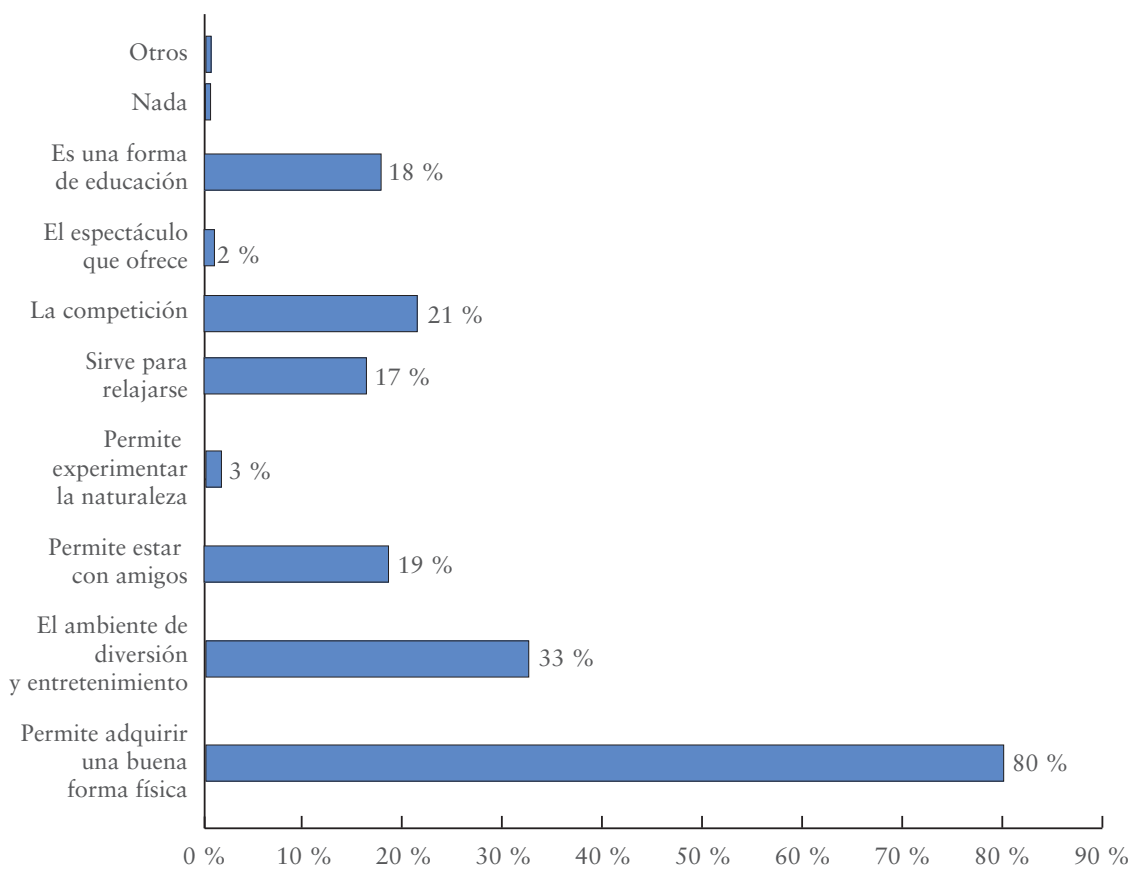


Figura 23. Actitudes desarrolladas por los practicantes de atletismo

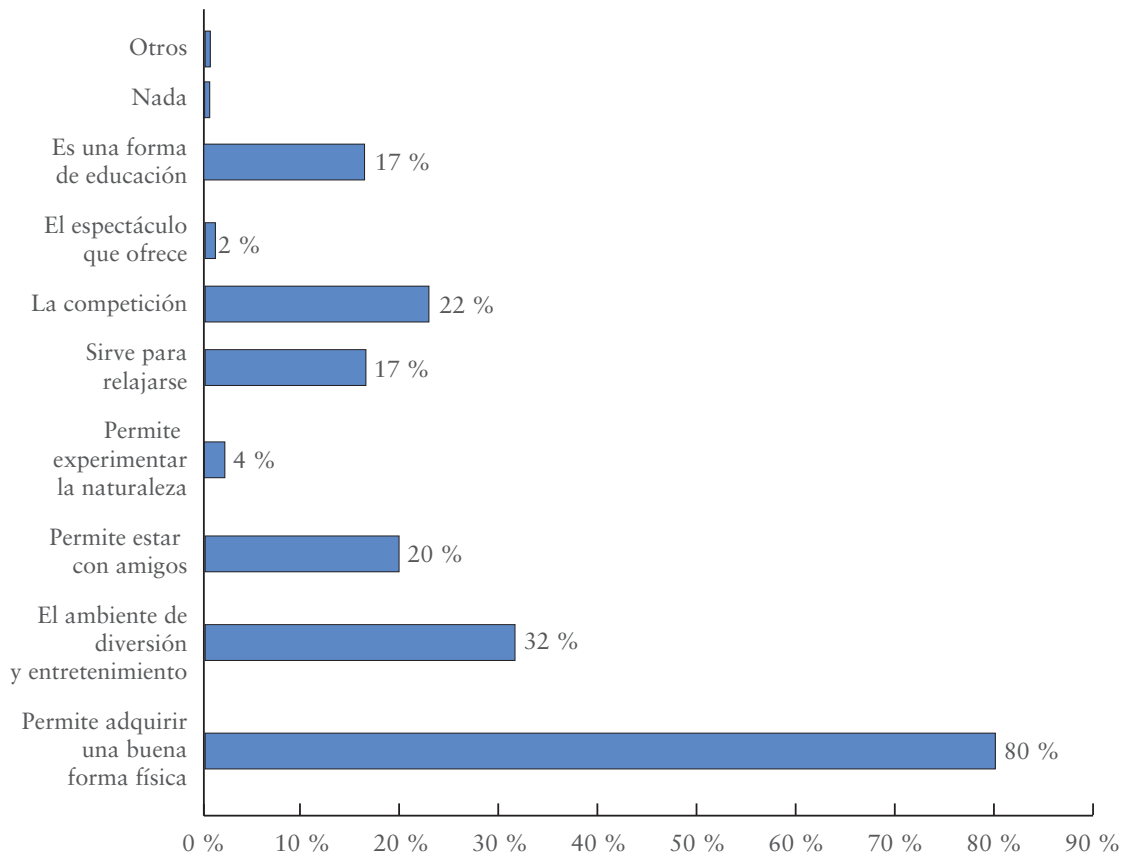

Figura 24. Actitudes desarrolladas por los practicantes de natación

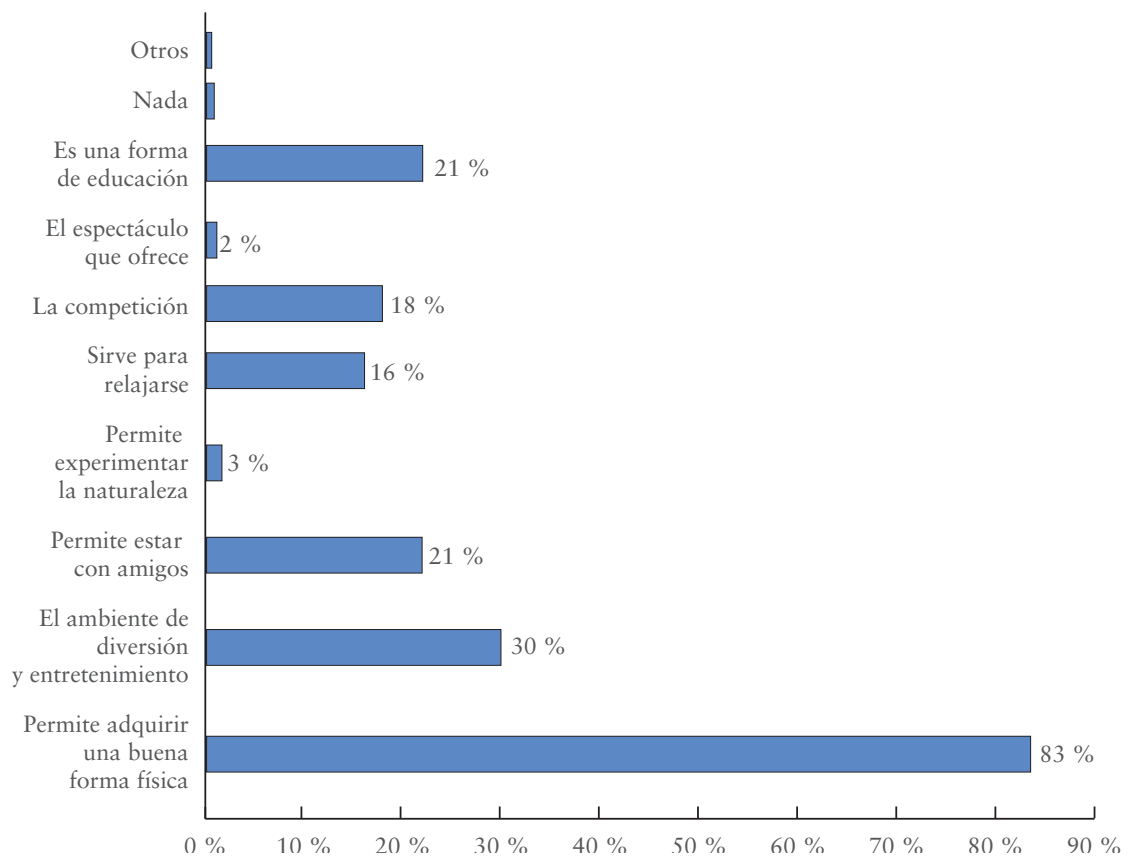


De acuerdo con las anteriores gráficas se puede observar que los escolares en general conciben la práctica del deporte como el medio que les permite adquirir una buena forma física. Esta preferencia concuerda con investigaciones en las que se demostró que los escolares de secundaria identifican el desarrollo del deporte con elementos de perfeccionamiento encaminado a desarrollar las capacidades físicas y habilidades específicas para cada deporte (Feu, Ibáñez y Gozalo, 2010).

A continuación en el orden de importancia está la concepción del deporte como diversión y entretenimiento. Es normal que esta perspectiva se replique en las clases de Educación Física, pues las investigaciones demostraron que a la hora de plantear los contenidos deportivos a los docentes les interesa principalmente que sus alumnos y alumnas se diviertan. Sin embargo, en contra de lo planteado anteriormente, llama la atención el alto porcentaje que afirma que considera más importante la asimilación de los gestos técnicos frente a los elementos tácticos. (Robles, Giménez y Abad (2010)., P 18.)

Igualmente, para los encuestados otro atractivo de la práctica de un deporte es la posibilidad de estar con amigos, que incluso supera el interés por competir.

No obstante, aunque quienes practican fútbol también piensan principalmente en mejorar su condición física, este interés es menor al ser comparado con el de los escolares que practican otras disciplina deportivas. Por lo demás, al igual que el resto de encuestados, los futbolistas manifiestan en segundo lugar su interés por la búsqueda de ambientes de diversión y entretenimiento a través de la práctica deportiva. Es importante destacar que en un porcentaje relevante de los escolares, sin importar la disciplina deportiva que practiquen, la consideran un medio educativo. 
Figura 25. Práctica futura: disposición por deporte

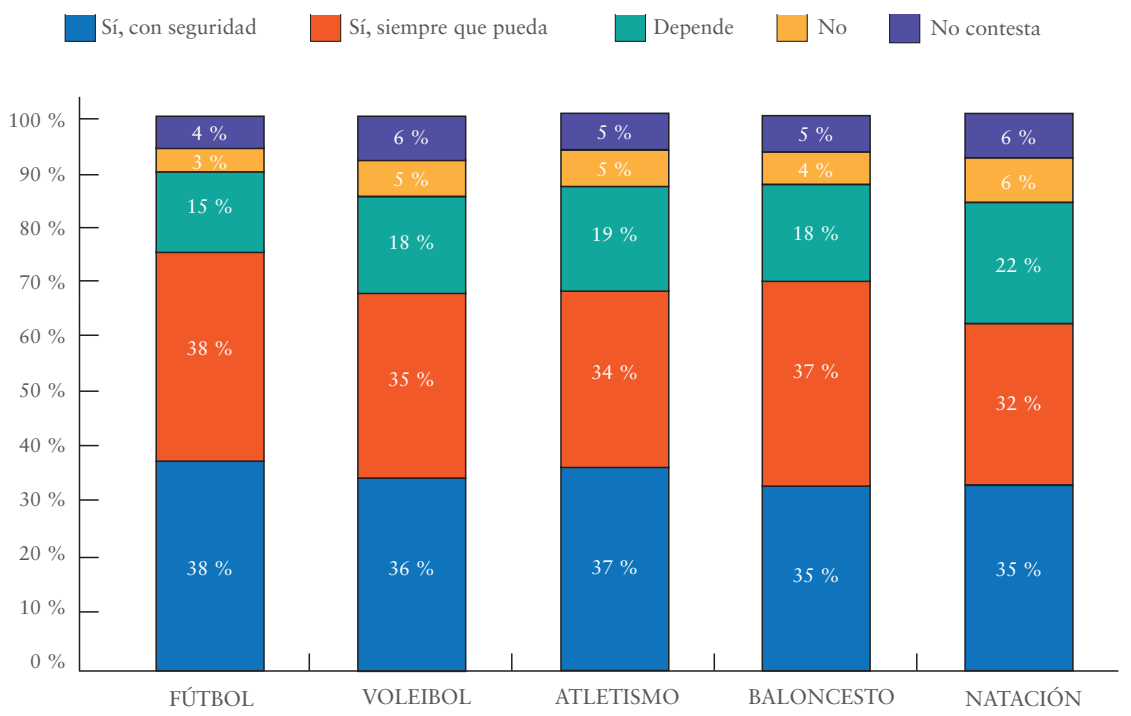

$\mathrm{Al}$ identificar la disciplina deportiva que preferirían seguir practicando a lo largo de la vida, la mayoría de los entrevistados refirieron el fútbol y el atletismo con toda seguridad.

Figura 26. Causas más relevantes que impedirían continuar las prácticas, por deporte

$\square$ Falta de afición $\square$ Falta de ayuda $\square$ Falta de formación $\quad \square$ Falta de instalaciones y medios

Falta de medios económicos $\square$ Falta de tiempo libre $\quad \square$ Otro

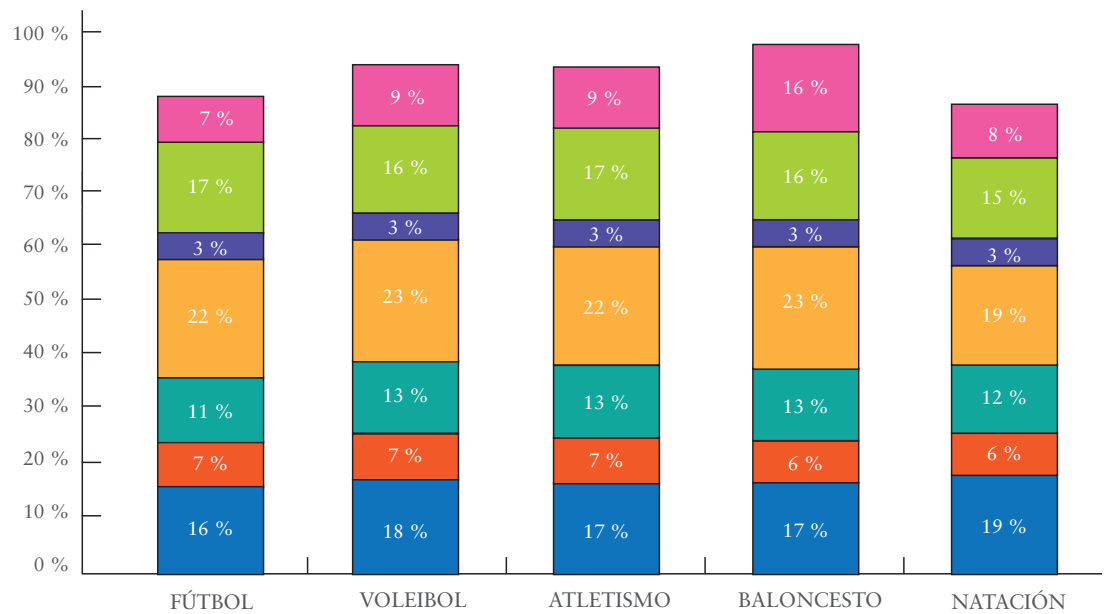


En la figura 26 se reconoce que la causa más relevante por la cual los escolares no continuarían practicando una disciplina deportiva, independientemente del deporte de su predilección, sería la falta de instalaciones y medios. Para los entrevistados que practican natación y voleibol la segunda causa de deserción sería la falta de afición. Mientras que para quienes practican fútbol la segunda causa por la que no continuarían jugándolo sería la falta de tiempo libre.

Se debe anotar que en los últimos años la inversión en infraestructura especializada para la realización de eventos deportivos a nivel competitivo se ha incrementado considerablemente en las diferentes regiones del país. Valdría la pena evaluar el tiempo de ocupación de tales escenarios, su destinación y utilización por parte de los escolares y la comunidad en general, al igual que su coincidencia con los intereses y expectativas de la población local.

Figura 27. Tendencia favorable a utilizar cada disciplina como deporte para todos

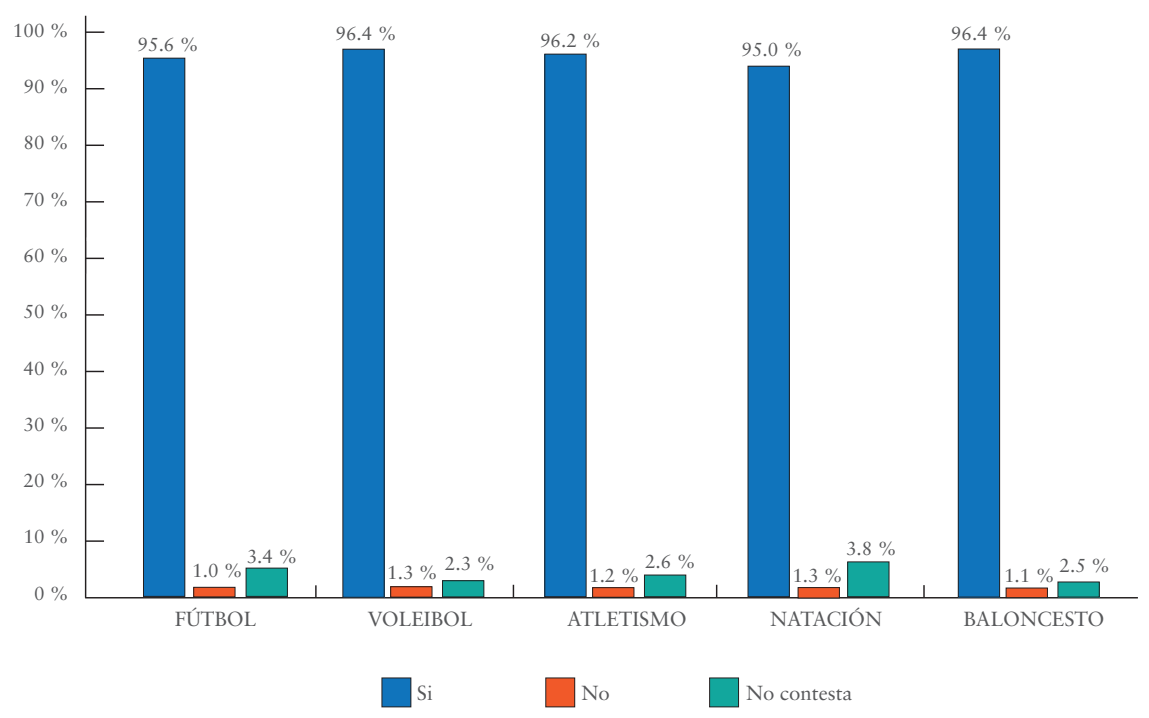

Respecto a la orientación de la práctica del deporte de acuerdo con el interés particular de los escolares se evidenció que más del $95 \%$ considera que su disciplina deportiva debe considerarse un deporte para todos: un espacio cívico que facilite procesos de 
integración e inclusión ciudadana, distante del deporte competitivo o de altos logros.

Figura 28. Opinión de los escolares practicantes, por disciplina, sobre dónde se adquieren los hábitos para la práctica deportiva

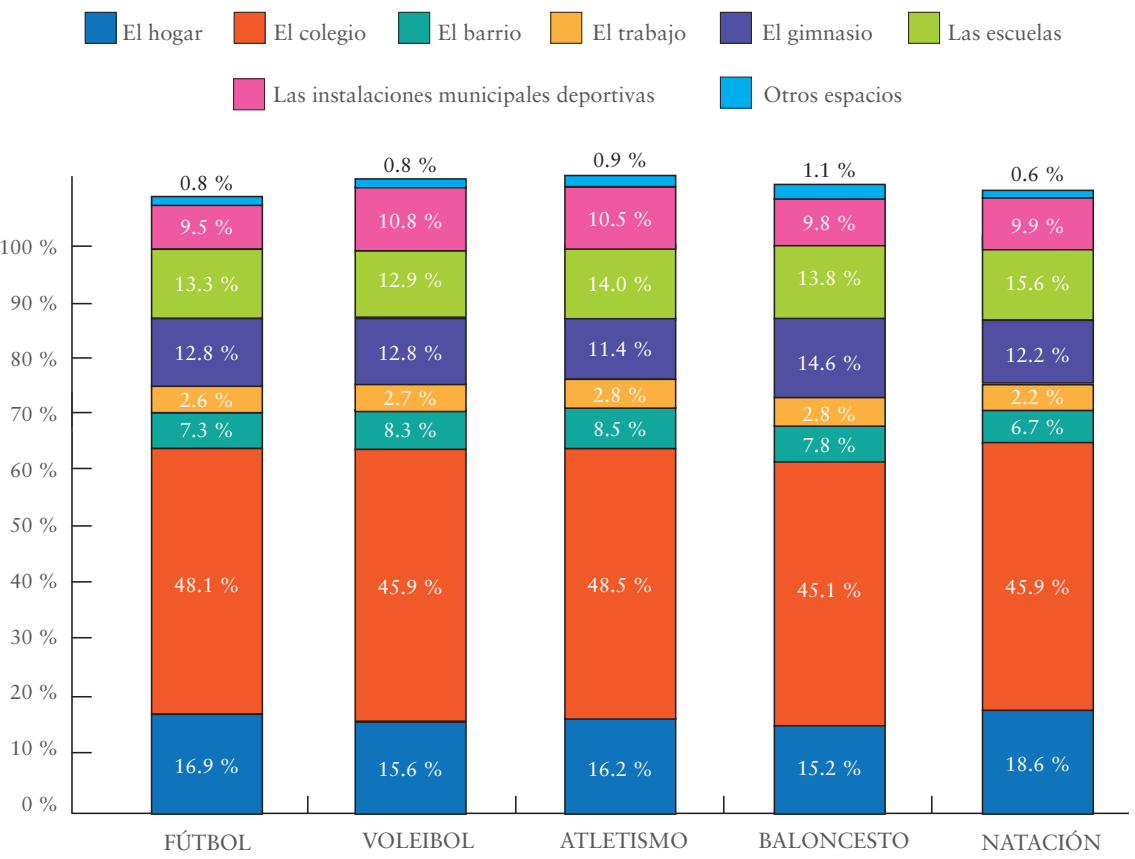

Como lo muestra la figura 28, los escolares creen que el lugar en donde se adquieren los hábitos para la práctica deportiva es el colegio. Esta respuesta nos lleva a establecer una relación directa con la ausencia de docentes especializados en el área de Educación Física, que tengan las competencias disciplinares para estimular la práctica regular de las actividades fisicodeportivas como parte de los hábitos de vida saludable.

De igual manera, faltan infraestructura y equipamiento, así como una propuesta curricular pertinente que incluya elementos comunes y a su vez responda a las particularidades de cada contexto. Una propuesta que trascienda de una formación técnica y de habilidades motrices hacia una formación integral que incluya aspectos 
biológicos, sicológicos y sociales para alcanzar una educación física de calidad.

Lo anterior es la base para la concreción curricular del área de Educación Física, siempre y cuando su elemento central promueva en los escolares la alfabetización física. Se trata en últimas de que el individuo logre adaptarse a las diferentes circunstancias de la vida diaria, interactuar de forma asertiva con los demás, adquirir confianza, seguridad y facilidad para la expresión, así como contribuir a su salud y bienestar, entre otros objetivos.

Por otra parte, los escolares coinciden en considerar que el hogar es el segundo lugar clave para la formación de los hábitos fisicodeportivos. Es decir que las actividades, gustos e intereses que tienen los niños, son el reflejo de aprendizajes y modelos provenientes del ámbito familiar. De hecho, en estudios como el de Romero y Amador (2007), se identificó la influencia que tienen especialmente las madres en la determinación y tendencia que los niños presentan respecto a la práctica o no de una actividad fisicodeportiva.

En cuanto al análisis por disciplina deportiva se identificó que en tercer lugar (después de la escuela y el hogar) quienes practican fútbol, en su gran mayoría del género masculino, consideran que el hábito se adquiere en las escuelas de formación deportiva. Mientras que quienes practican baloncesto y voleibol, en su gran mayoría del género femenino, consideran que la adquisición de los hábitos se logra en el gimnasio. 
Figura 29. Actividades a incluir en la clase de Educación Física, según los practicantes de los principales deportes

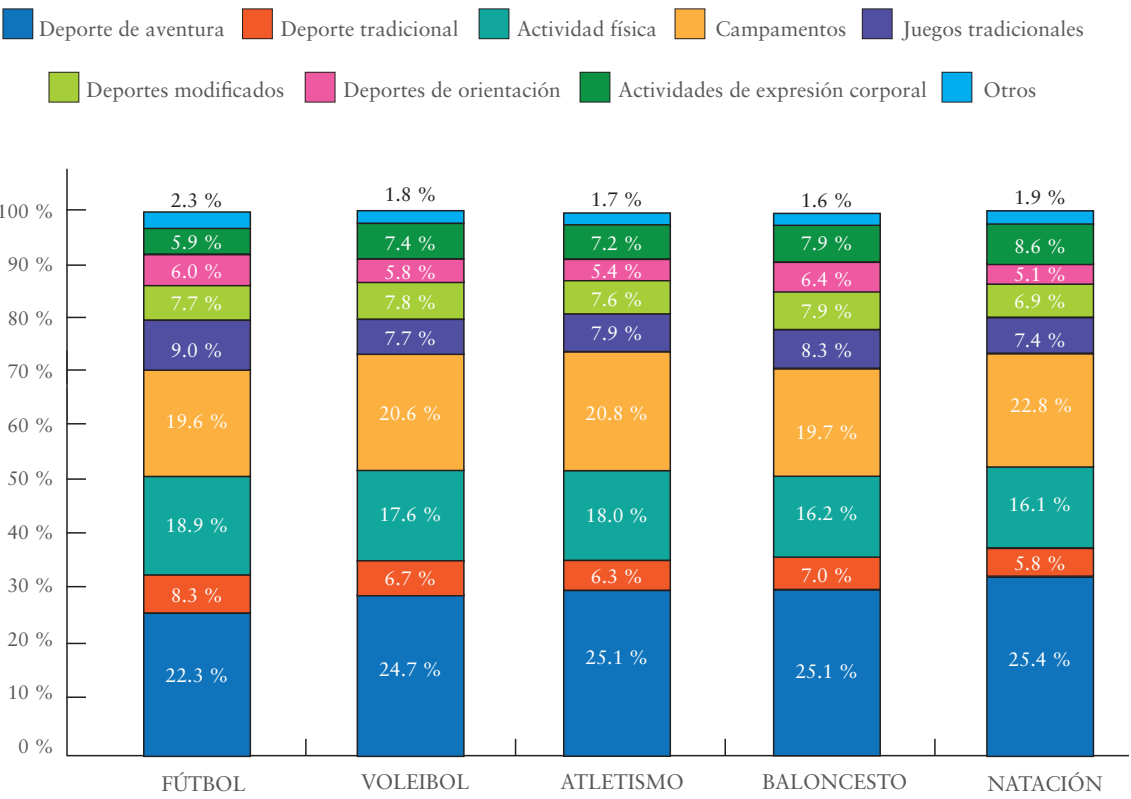

En la pregunta que se realizó para conocer las preferencias sobre nuevas actividades dentro de la clase de Educación Física se ofreció la opción de señalar tres respuestas. La mayoría indicó que le agradaría la inclusión de deportes de aventura, campamento y actividad física.

Respecto a las tendencias recreativas que los escolares quisieran incluir en la clase de Educación Física, con la posibilidad de señalar tres respuestas, la totalidad coincide en afirmar que les agradaría la recreación deportiva, seguida por la recreación ambiental y la laboral. 
Figura 30. Tendencias de corrientes recreativas que los practicantes de cada disciplina deportiva quisieran incluir en las clases de Educación Física

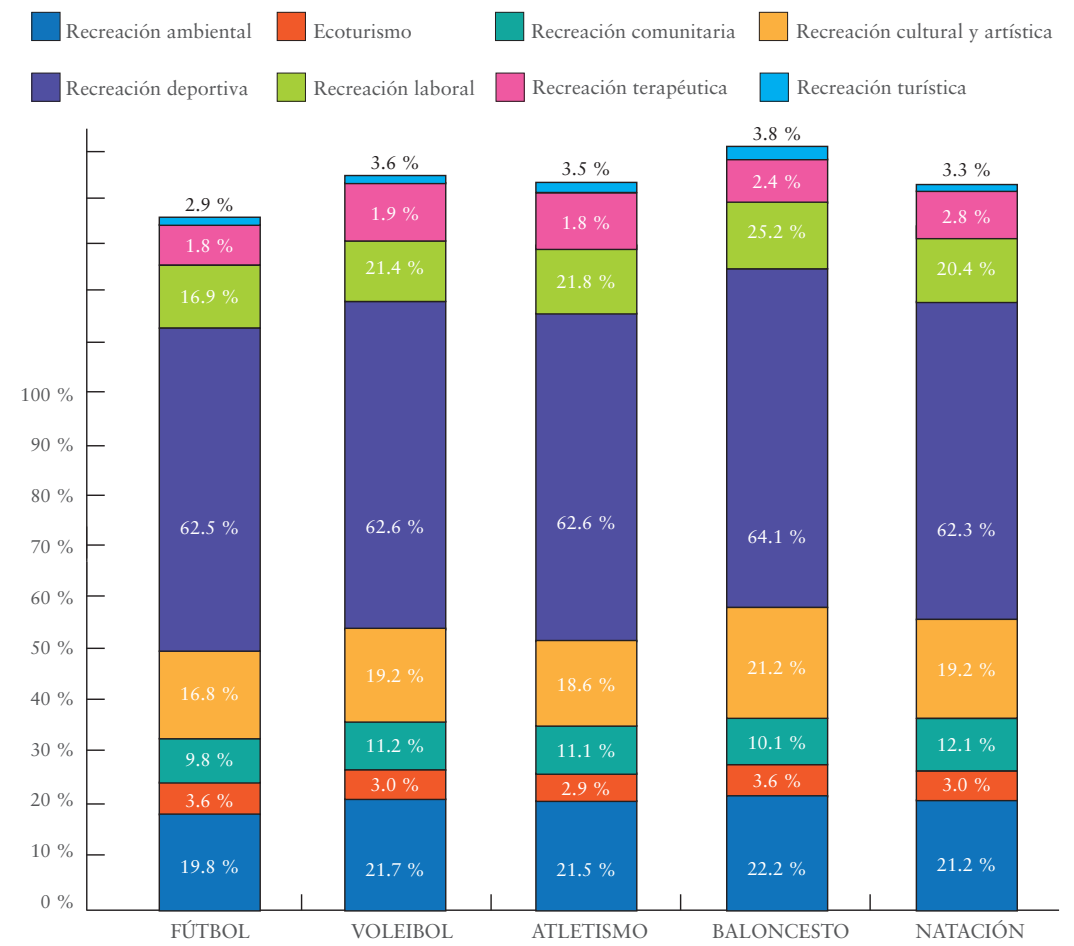

Figura 31. Compañía con que suelen practicar la disciplina deportiva
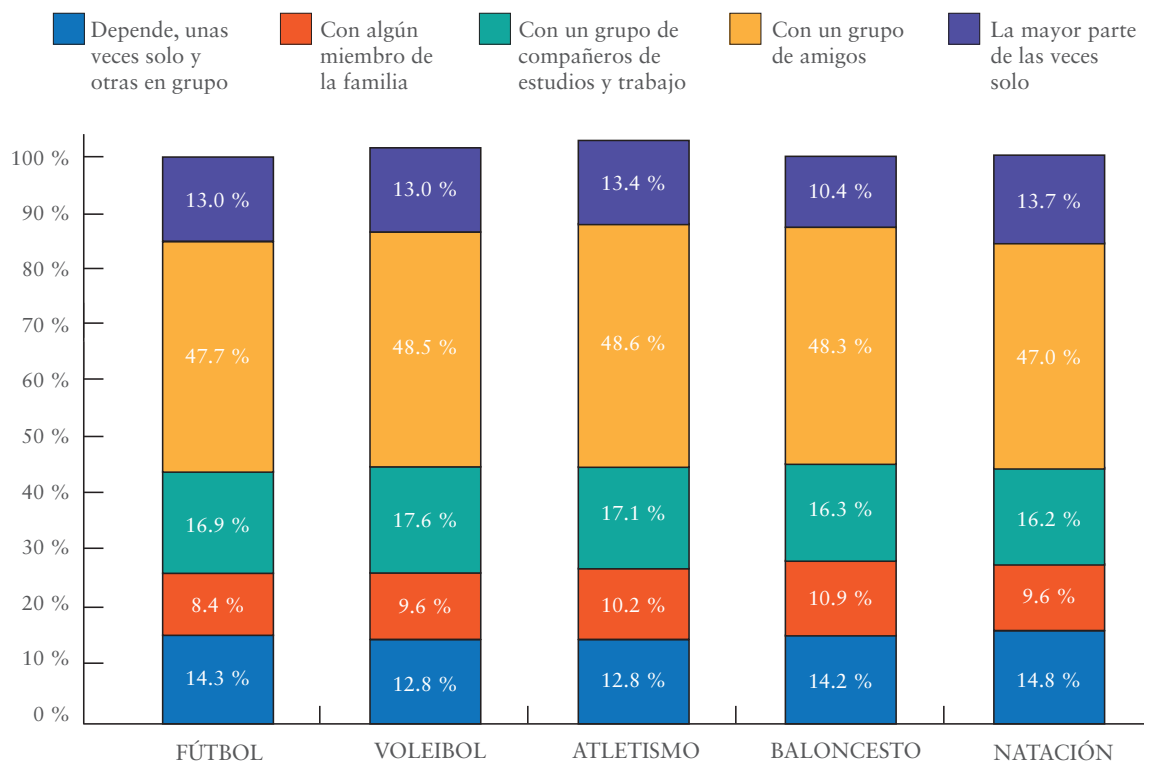
A la pregunta “¿Con quién realiza la práctica deportiva?” la totalidad de los escolares afirmó que lo hacen con un grupo de amigos/amigas. Esto evidencia nuevamente que el deporte es un espacio apropiado para conocer y afianzar las relaciones interpersonales, especialmente durante la época escolar.

\section{Interés por la participación futura en actividades fisicodeportivas}

Una de las preguntas de mayor importancia en el estudio. Se puede inferir que el $67 \%$ de los encuestados manifestaron su disposición a participar en eventos deportivos futuros pues un $32.1 \%$ afirma que participaría con toda seguridad y un $34.9 \%$ dice que lo haría siempre que pudiera.

Figura 32. Interés por participar en actividades fisicodeportivas futuras

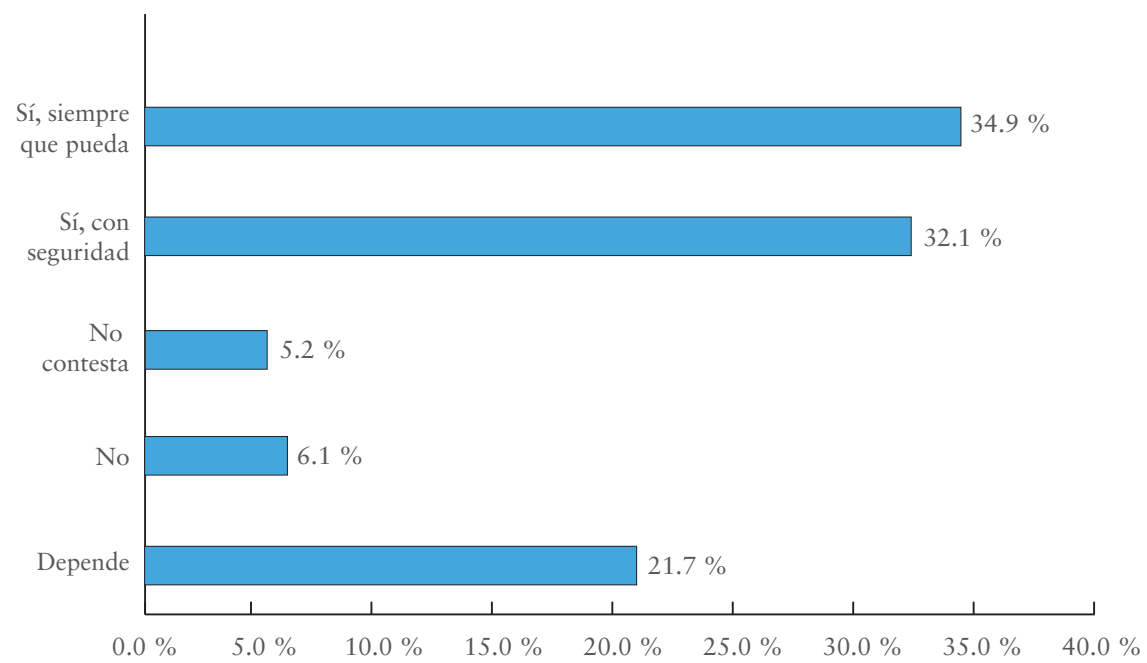

